\title{
Um Panorama de Pesquisas do Campo da Educação Sobre a Lua e suas Fases
}

\section{An Overview on Researches on the Field of Education About the Moon and its Phases}

iD Paula Cristina da Silva Gonçalves ${ }^{1}$

iD Paulo Sérgio Bretones ${ }^{2}$

\begin{abstract}
'Universidade Estadual de Campinas (Unicamp), Programa de Pós-Graduação Multiunidades em Ensino de Ciências e Matemática, Campinas, SP, Brasil. Autor correspondente: paulacsgsimon@yahoo.com.br

${ }^{2}$ Universidade Federal de São Carlos (UFScar), Centro de Educação e Ciências Humanas, São Carlos, SP, Brasil.
\end{abstract}

Resumo: Apresentamos um panorama de pesquisas sobre a Lua e suas fases a partir de teses, dissertações, artigos publicados em periódicos, e trabalhos apresentados em eventos relacionados ao ensino e à Educação em Astronomia nacionais. Neste levantamento buscou-se verificar as produções, organizá-las e analisá-las especialmente em relação ao nível escolar destinado e ao foco temático, com ênfase sobre os recursos didáticos, e conteúdo e método. Tal levantamento possibilitou identificar as produções referentes ao tema e conhecer algumas tendências e lacunas da pesquisa a partir de três diferentes tipos de publicações de trabalhos acadêmicos. Os dados mostram que Lua e suas fases são temas bastante abordados, com a maior parte dos trabalhos concentrados no Ensino Fundamental, especialmente nos Anos Finais, e que Conteúdo e Método é o foco com maior incidência. Pretende-se, assim, colaborar com a divulgação de tais pesquisas, discutir sobre seus resultados e indicar possibilidades para futuras pesquisas.

Palavras-chave: Pesquisa bibliográfica; Fases da lua; Educação em astronomia; Ensino de astronomia.

Abstract: We present an overview of researches about the Moon and its phases from theses and dissertations, articles published in national journals and works presented in meetings related to Astronomy teaching and education. In this survey, we aimed to verify the productions, organize and analyze them especially about the School Level and the Focus of the Study, with emphasis on the Teaching Materials and Content and Method. Such survey makes it possible to identify the productions referring to the theme and to know some trends and research gap, from three different types of publications. The data shows that Moon and its phases is a thoroughly addressed subject, with most of the works concentrated in Elementary School, especially in the Final Years and that Content and Method is the focus with greater incidence. It is intended to collaborate with the dissemination of such researches to discuss its results and indicate possibilities for future researches.

Keywords: Bibliographic research; Phases of the moon; Astronomy education; Astronomy teaching.

Recebido em: 17/01/2019

Aprovado em: 16/06/2019

e-ISSN 1980-850X. Todo o conteúdo deste periódico está licenciado com uma licença Creative Commons (CC Atribuição 4.0 Internacional), exceto onde está indicado o contrário. 


\section{Introdução}

Tendo em vista que a Lua é o astro mais brilhante visível no céu noturno, trata-se de um tema acessível e que pode ser bastante abordado no ensino de Astronomia, propiciando potencialmente avanços em sua discussão didático-pedagógica.

No que se refere à prática de sala de aula, levando-se em conta que a explicação sobre as fases da Lua é um tema muito abordado e bem conhecido por professores com uso de quadro negro, bolas de isopor para representar Sol, Terra e Lua e até softwares, ainda ficam algumas perguntas sobre recursos didáticos e metodologias de ensino: será que uma boa variedade de recursos e metodologias são bem conhecidos, divulgados e mesmo usados em sala de aula? Será que são eficientes para o nível escolar em que são desenvolvidos? Teria algo diferente a ser proposto?

Alguns trabalhos realizados sobre levantamentos e análises de pesquisas em educação em Astronomia indicam que o tema Sistema Sol-Terra-Lua é, de fato, um dos mais abordados (BRETONES; MEGID NETO, 2011; BRETONES; ORTELAN, 2012; BRETONES; JAFELICE; HORVATH, 2016; LELLIOTT; ROLLNICK, 2010). Neste tema estão os conteúdos referentes aos movimentos da Terra, fases da Lua e eclipses, estações do ano, marés, entre outros.

Muito já foi publicado sobre concepções de estudantes e professores sobre os mais variados temas, e as fases da Lua integram esse conjunto de obras. Podem ser citados vários exemplos na literatura internacional:Lightman e Sadler (1993), Schoon (1992), Trumper (2000), e Zeilik, Schau e Mattern (1998). Especificamente sobre esse conteúdo também podem ser citados Barnett e Morran (2002), Baxter (1989, 1998), Camino (1995), Fanetti (2001), Lindell e Olson (2002), Navarro (2001), Quílez, Peña e Begoña (2005), Stahly, Krockover e Shepardson (1999), e, Trundle, Atwood e Christopher (2002).

Contudo, Pasachoff (2001), discutindo o ensino de Astronomia norte-americano, considera que fases da Lua são estudadas e trabalhadas em demasia, apesar de, ao mesmo tempo, os estudantes terminarem sua escolarização sem entender de forma adequada esse conteúdo. $O$ autor questiona se insistir nessa questão é limitar o ensino a pouco, não avançando sobre questões de Astronomia contemporânea, nem sobre questões mais amplas do universo, o que limita os estudantes a um mínimo denominador comum. Isso significa que, mesmo sendo um tema relativamente mais abordado no ensino, em comparação com os demais da Astronomia, não se pode dizer que tem sido bem-sucedido em seu processo de ensino-aprendizagem.

Entendendo que a situação dos estudantes brasileiros não está muito diferente, nos interessa verificar quais são as estratégias e os recursos privilegiados ao longo dos diferentes níveis escolares para o ensino e a aprendizagem do tema. Para tanto, propomonos a investigar o que se tem produzido nas pesquisas a partir de três bases distintas: teses e dissertações, artigos de periódicos e atas de eventos.

Nesse sentido, esta pesquisa poderá contribuir para conhecer o coletivo e o estilo de pensamento em torno do ensino deste tema no Brasil. Pode esclarecer quais são os focos temáticos e os níveis escolares mais abordados e comparar com outras produções nacionais e internacionais, buscando reflexões em torno dos processos de ensino e aprendizagem por meio das metodologias e dos recursos didáticos utilizados. 


\section{Metodologia}

Esta pesquisa foi desenvolvida utilizando a Análise de Conteúdo (BARDIN, 2011) e organizada segundo os três polos cronológicos, que compreendem a pré-análise, a exploração do material e o tratamento dos resultados e, por fim, a inferência e a interpretação.

Na pré-análise, foi definido o corpus da pesquisa, composto a partir da verificação de teses e dissertações, artigos publicados em periódicos e trabalhos apresentados em eventos. As fontes desses dados foram escolhidas de acordo com a proximidade ao tema, utilizando também como referência alguns trabalhos de Estado da Arte e de revisão de literatura já produzidos em Educação em Astronomia (BRETONES; MEGID NETO, 2005, 2011; BRETONES; ORTELAN, 2012; BRETONES; MEGID NETO; CANALLE, 2006; BUSSI; BRETONES, 2013; FERNANDES; NARDI, 2015; IACHEL; NARDI, 2010; MARRONE JR.; TREVISAN, 2009; ORTELAN; BRETONES, 2012).

No que diz respeito a teses, dissertações e artigos, realizamos análises mais extensivas, verificando também aqueles em que a abordagem do tema se dava conjuntamente à exposição de outros pontos da Astronomia, considerando que são trabalhos mais extensos e, portanto, passíveis de abordagem significativa, ainda que a Lua e suas fases não fossem o foco. Os trabalhos contidos em atas de eventos, por sua vez, foram selecionados apenas quando a temática foi encontrada de forma direta e explícita, dado o volume de produções dos eventos selecionados e os objetivos principais deste trabalho, delimitando, assim, nosso corpus de análise.

Na sequência, foi desenvolvida a exploração dos materiais por meio de leitura flutuante. Ademais, foi feito o tratamento dos resultados, que foram categorizados utilizando planilhas eletrônicas com a identificação dos descritores Níveis escolares e Foco temático, conforme proposto por Megid Neto (1999).

Os níveis escolares compreenderam as etapas: Educação Infantil (EI); Anos Iniciais do Ensino Fundamental (EF1); Anos Finais do Ensino Fundamental (EF2); Ensino Médio (EM); Ensino Superior (ES); Geral, no caso dos trabalhos que podem ser considerados para qualquer nível de ensino, sem se dedicar a um específico; Não Escolares, categoria que engloba estudos que se desenvolveram em ambientes como observatórios, planetários, entre outros, fora do contexto da estrutura escolar de educação; Não se Aplica (NP), usada quando a questão do nível escolar não é encontrada.

Em relação ao foco temático, procuramos classificar cada trabalho a partir da identificação do tema principal ou privilegiado (MEGID NETO, 1999). Além dos focos propostos pelo autor, incluímos o aspecto Conteúdo Específico para os trabalhos que abordam o tema exclusivamente dessa maneira (Quadro 1): 
Quadro 1 - Descrição dos focos temáticos utilizados

\begin{tabular}{|l|l|}
\hline \multicolumn{1}{|c|}{ Foco Temático } & \multicolumn{1}{c|}{ Descrição } \\
\hline Currículos e Programas & Currículos oficiais ou escolares e programas de ensino. \\
\hline Conteúdo e Método & Metodologias de ensino para tratamento de conteúdos sobre a Lua e suas fases. \\
\hline Recursos Didáticos & Utilização ou avaliação de algum recurso didático específico. \\
\hline $\begin{array}{l}\text { Características do Profes- } \\
\text { sor }\end{array}$ & $\begin{array}{l}\text { Conhecimentos prévios, concepções, representações, percepções, sentidos, significados ou mo- } \\
\text { delos de pensamento de docentes. }\end{array}$ \\
\hline Características do Aluno & $\begin{array}{l}\text { Conhecimentos prévios, concepções, representações, percepções, sentidos, significados ou mo- } \\
\text { delos de pensamento de alunos. }\end{array}$ \\
\hline Formação de Conceitos & Análise de conceitos científicos e técnicos de alunos ou professores. \\
\hline Formação de Professores & Projetos e cursos para professores atuando em diferentes níveis escolares. \\
\hline Conteúdos Específicos & $\begin{array}{l}\text { Explicações sobre determinado conteúdo específico sobre astros, suas características, suas pro- } \\
\text { priedades e seus fenômenos. }\end{array}$ \\
\hline Outros & Análises de avaliações ou produções sobre Estado da Arte. \\
\hline
\end{tabular}

Fonte: adaptado de Megid Neto (1999).

O material foi organizado, selecionamosas fontes extraímos as produções relacionadas ao tema de interesse a partir do título, do resumo e das palavras-chave. Posteriormente, por meio da leitura flutuante e das técnicas da Análise de Conteúdo, analisamos o material coletado (BARDIN, 2011). Por fim, a pesquisa conclui-se com a inferência e interpretação dos dados encontrados, compartilhando as tabelas e os quadros que emergiram da análise desse material.

\section{Teses e Dissertações}

A seleção das teses e dissertações analisadas neste trabalho foi definida a partir do Banco de Teses e Dissertações em Educação em Astronomia (BTDEA), que preserva dados atualizados sobre esse tipo de produção na Educação em Astronomia no Brasil. Analisamos as produções de 1973 até 2015, totalizando 158 trabalhos. Para auxiliar essa investigação foram consultados o trabalho de Bretones e Megid Neto (2005), que analisou as teses e as dissertações de 1973 até 2002, utilizando uma variedade de descritores, e a pesquisa de Bretones e Ortelan (2012), que estudou o período de 1973 até 2010, com foco da análise para os temas e conteúdos abordados por essas pesquisas, com um volume total de 70 trabalhos analisados.

Bretones e Megid Neto (2005) verificaram que no período analisado os focos temáticos de maior incidência foram: Conteúdo e Método, Concepções do Professor, Currículo e Programas, e Recursos Didáticos. Neste trabalho, o foco temático concepções do professor está contido em características do professor. Bretones e Ortelan (2012) constataram que o tema referente ao sistema Sol-Terra-Lua, no qual os conteúdos dedicados à Lua e a suas fases estão inseridos, é o mais abordado entre as teses e as dissertações analisadas.

Sendo assim, para este levantamento, localizamos apenas seis trabalhos relacionados especificamente ao tema Lua e suas fases': Fagundes (2014), Ferreira (2015), Lago (2013),

'Os documentos recuperados pela pesquisa estão referenciados em ordem alfabética de autor em anexos no final deste artigo. 
Lima (2006), Puzzo (2005) e Valente (2007). Encontramos também 36 estudos com abordagem considerável ao tema e discussão de outros conteúdos relacionados à Educação em Astronomia, totalizando 42 trabalhos (26,6\%). A lista e a classificação dessas pesquisas se encontram no Anexo A.

Sobre o descritor nível escolar, alguns trabalhos foram classificados, quando necessário, em mais de uma categoria. Dessa maneira, temos a seguinte distribuição: Ensino Fundamental, 27-64,3\%, Ensino Médio, 16-38,1\%, e Ensino Superior, 9-21,4\%. É importante notar que não foi localizado trabalho dedicado à Educação Infantil no período analisado e que um trabalho foi considerado como Geral. Ainda, dentro desta análise, dos 27 textos destinados ao Ensino Fundamental, 6 abordam os Anos Iniciais e Finais de forma conjunta, 8 dedicam-se aos Anos Iniciais, e 13 aos Anos Finais.

A Tabela 1 mostra os dados organizados de forma cruzada entre os Níveis Escolares e os Focos Temáticos, exibindo, assim, o que se destaca nos diferentes níveis. É importante lembrar que os números ultrapassam o total de trabalhos, visto que muitos abordam mais de um Nível Escolar, sendo contados mais de uma vez, conforme as classificações do Anexo A.

Tabela 1 - Distribuição das teses e das dissertações sobre Lua e suas fases por Nível Escolar e Foco Temático

\begin{tabular}{|c|c|c|c|c|}
\hline Nível (N - \%) & Foco & N. & \% nível & $\%$ total \\
\hline El (0-0) & - & - & - & - \\
\hline \multirow[t]{7}{*}{ EF (27-64,3 \%) } & Conteúdo e método & 6 & 22,2 & 14,3 \\
\hline & Recursos didáticos & 6 & 22,2 & 14,3 \\
\hline & Formação de professores & 6 & 22,2 & 14,3 \\
\hline & Características do professor & 6 & 22,2 & 14,3 \\
\hline & Currículos e Programas & 2 & 7,4 & 4,7 \\
\hline & Características do aluno & 2 & 7,4 & 4,7 \\
\hline & Formação de conceitos & 1 & 3,7 & 2,4 \\
\hline \multirow[t]{6}{*}{ EM (16-38,1 \%) } & Conteúdo e método & 6 & 37,5 & 14,3 \\
\hline & Formação de professores & 4 & 25 & 9,5 \\
\hline & Recursos didáticos & 3 & 18,7 & 7,1 \\
\hline & Características do professor & 1 & 6,2 & 2,4 \\
\hline & Currículos e Programas & 1 & 6,2 & 2,4 \\
\hline & Formação de conceitos & 1 & 6,2 & 2,4 \\
\hline \multirow[t]{4}{*}{ ES (9-21,4 \%) } & Formação de professores & 5 & 55,5 & 11,9 \\
\hline & Recursos didáticos & 3 & 33,3 & 7,1 \\
\hline & Características do professor & 1 & 11,1 & 2,4 \\
\hline & Características do aluno & 1 & 11,1 & 2,4 \\
\hline G $(1-2,4 \%)$ & Outros & 1 & - & 2,4 \\
\hline
\end{tabular}

Fonte: elaborada pelos autores.

É possível verificar, a partir da Tabela 1, que, nos níveis da Educação Básica, os três temas predominantes são Conteúdo e Método, Recursos Didáticos e Formação de Professores. O primeiro não aparece em nenhuma das pesquisas referentes ao nível do Ensino Superior, que, por sua vez, tem como tema predominante a Formação de Professores.

No Ensino Fundamental, os focos estão distribuídos entre sete e divididos entre os quatro primeiros de forma bastante similar. Isso não acontece com os estudos dedicados ao Ensino Médio e ao Ensino Superior, que estão mais concentrados. 
Em uma análise mais geral, a Tabela 2 mostra os trabalhos organizados por Focos Temáticos. Nessa classificação, apenas dois apresentaram mais de um, por isso, os números ultrapassam o total de documentos (42). Os demais foram classificados em apenas um foco.

Tabela 2 - Distribuição das teses e das dissertações sobre Lua e suas fases por Foco Temático

\begin{tabular}{lccc}
\hline Foco & N. & \% \\
\hline Conteúdo e Método & 11 & 26,2 \\
Formação de Professores & 11 & 26,2 \\
Recursos Didáticos & 9 & 21,4 \\
Características do Professor & 6 & 14,3 \\
Características do Aluno & 2 & 4,7 \\
Currículos e Programas & 2 & 4,7 \\
Formação de Conceitos & 2 & 4,7 \\
Outros (Estado da Arte) & 1 & 2,4 \\
\hline
\end{tabular}

Fonte: elaborado pelos autores.

Ao observar os Focos Temáticos abordados, de maneira geral, em relação ao total de trabalhos, o que temos é uma predominância do tema Conteúdo e método e Formação de professores, com 11 trabalhos cada (26,2\%). Logo a seguir, temos o foco Recursos didáticos, com 9 trabalhos (21,4\%). Esses três temas correspondem à maioria das teses e das dissertações analisadas que se relacionam com o tema Lua e suas fases. Os demais focos presentes são: Características do Professor, encontrado em 6 estudos (14,3\%); Currículos e Programas, visto em 2 materiais (4,7\%); Formação de Conceitos, presente em duas publicações (4,7\%); e Outros, verificado em um dos textos que tratava sobre o Estado da Arte, $(2,4 \%)$.

Como vimos, temos 11 trabalhos com o Foco Temático Conteúdo e método. Suas propostas sugerem?

- construção de modelos com materiais de baixo custo: Amaral (2015), Lago (2013), Pellenz (2015), Pesquero (2015), Queiroz (2005), Silva (2015);

- observação: Debom (2010), Lago (2010), Lima (2006), Pellenz (2015), Santiago (2015), Silva (2014);

- aulas expositivas com vídeos ou slides: Amaral (2015), Menezes (2010), Pesquero (2015), Silva (2015);

- uso de tecnologias computacionais como simuladores: Debom (2010), Pesquero (2015);

- construção de materiais táteis para alunos com deficiência visual: Santos (2001); e,

- visita a planetário: Menezes (2010).

Em relação aos Recursos Didáticos, a maioria dos materiais direciona-se para a modelização do sistema Sol-Terra-Lua. Alguns textos sugerem o uso de tecnologias computacionais: Campos (2004), Fagundes (2014), e Silva (2010); outros propõem a utilização de kits e/ou manuais: Amaral (2008), Carrilho (2015) e Soares (2010). Caetano (2007) indica o uso do corpo dos alunos; um trabalho (HERZOG, 2009) recomenda materiais de baixo custo; Bernardes (2009) aconselha a lida com ferramentas táteis para o ensino de alunos com deficiência visual, e Caetano (2007) inclui a observação da Lua.

${ }^{1}$ As referências completas desses trabalhos encontram-se no Anexo A, ao final deste artigo. 
Os trabalhos relacionados aos professores, de forma geral, seguem a mesma questão central. Estão estruturados em torno da melhoria do conhecimento dos professores em relação aos conteúdos em si.

Podemos verificar que a maior parte dos trabalhos analisados fazem discussões e propostas direcionadas à prática docente. Poucos se dedicam aos processos de pensamento dos alunos e aos aspectos curriculares.

A maior parte das propostas se relaciona à construção do modelo do Sistema SolTerra-Lua. Seis indicam utilizar alguma observação da Lua em suas metodologias. Delas, três sinalizam para uma prática que acompanhe o processo de mudanças de fases: Lago (2010), Lima (2006), e Pellenz (2015). As outras três são pontuais: duas tencionam a verificação das crateras: Debom (2010) e Santiago (2015), e Silva (2015) objetiva encontrar sua localização no céu. Na maioria das teses e das dissertações em que a observação é indicada, trata-se de uma parte pequena do texto, incluída entre outras estratégias privilegiadas ou entre o estudo de outras questões no céu.

\section{Artigos}

O levantamento desenvolvido em relação aos artigos selecionou trabalhos de periódicos nacionais que publicam estudos sobre a Educação em Astronomia. Essa seleção está organizada por revista pesquisada e por centralidade, ou não, na abordagem do tema da Lua e de suas fases. Nesse processo de investigação inicialmente foram consultados os trabalhos de lachel e Nardi (2010) e Marrone Junior e Trevisan (2009).

Os periódicos selecionados foram organizados no Quadro 2 e a lista com a classificação dos trabalhos estão no Anexo B, tendo em vista o período analisado.

Quadro 2 - Periódicos selecionados, período consultado e trabalhos encontrados em relação à centralidade do tema

\begin{tabular}{|c|c|c|c|}
\hline Nome do Periódico & Período (edição e ano) & Lua & $\begin{array}{c}\text { Lua entre } \\
\text { Outros }\end{array}$ \\
\hline Alexandria & $1(2008)$ a 8 (n. 3, 2015) & 0 & 1 \\
\hline Caderno Brasileiro de Ensino de Física & $1(1984)$ a $32($ (n. 3, 2015) & 3 & 7 \\
\hline Ciência \& Educação & 1 (1998) a 21 (n. 4, 2015) & 1 & 0 \\
\hline Ensaio: pesquisa em educação em ciências & 1 (1999) a 17 (n. esp., 2015) & 0 & 1 \\
\hline Experiências em Ensino de Ciências & $1(2006)$ a $10($ (n. 3, 2015) & 0 & 1 \\
\hline Física na Escola, A & $1(2000)$ a $13(2012)$ & 2 & 0 \\
\hline Investigações em Ensino de Ciências & 1 (1996) a 20 (n. 3, 2015) & 0 & 1 \\
\hline Revista Brasileira de Ensino de Física & 1 (1979) a 37 (n. 4, 2015) & 5 & 2 \\
\hline Revista Latino-Americana de Educação em Astronomia & $1(2004)$ a $20(2015)$ & 9 & 17 \\
\hline \multicolumn{2}{|l|}{ Totais } & 20 & 32 \\
\hline
\end{tabular}

Fonte: elaborado pelos autores. 
No que se refere à Revista Latino-Americana de Educação em Astronomia (RELEA), na análise de suas 20 edições encontramos 9 trabalhos que se relacionam diretamente com o tema fases da Lua, que são: Darroz, Rosa e Vizzoto (2013); Darroz et al. (2012); Fagundes, Silva e Barroso (2015); Giovannini, Pellenz e Catelli (2014); lachel, Langhi e Scalvi (2008); Martins e Langhi (2012); Queiroz, Sousa e Machado (2009); Saraiva, Silveira e Steffani (2011); Saraiva et al. (2007). Constatamos ainda 17 artigos que incluíram esse tema juntamente a outros, organizados e referenciados no Anexo B.

$\mathrm{Na}$ Revista Brasileira de Ensino de Física (RBEF) foram localizados cinco artigos com Lua e suas fases como tema principal. Todos apresentam como foco o Conteúdo Específico. Três têm natureza teórica de aprimoramento de conhecimentos: Aguiar, Baroni e Farina (2009), Silveira (2001), Tonel e Marranghello (2013). Os outros dois apresentam possibilidades metodológicas, sem especificar para qual nível de ensino se dirigem: Kulesza (1988) e Teixeira Junior (1980).

No Caderno Brasileiro de Ensino de Física (CBEF) encontramos três trabalhos nos quais questões sobre Lua foram abordadas como objeto principal. Porém, apresentam como foco o Conteúdo Específico sobre o tema, com objetivo informativo ou com o propósito de explicação de fenômenos. Foram eles: Almeida (2012), Lopes (2014), e Silveira (2003). No caso de artigos cujo tema central não era as fases da Lua, mas tinham presença relevante desse assunto, excluindo os textos relacionados às análises de livros didáticos, localizamos sete trabalhos.

Verificamos a revista A Física na Escola e encontramos apenas dois artigos relacionados ao tema Lua. Ambos se direcionavam às explicações de Conteúdos Específicos (SILVEIRA; MEDEIROS, 2006; SILVEIRA; SARAIVA, 2008).

No que se refere à revista Ciência e Educação (C\&E), há somente o trabalho de Kriner (2004). Essa produção mencionava diretamente o assunto.

Também analisamos as publicações da Revista Brasileira de Pesquisa em Educação em Ciências (RBPEC). Nela, apenas dois trabalhos tratam sobre o tema fases da Lua, entre outras questões (BRETONES; COMPIANI, 2012; MACHADO; QUEIROZ, 2012). Não localizamos trabalho, nessa revista, que pesquisasse essencialmente as fases da Lua e seu ensino.Em relação ao Ensino Fundamental, cujo total de textos é 20 (38,4\%), cinco artigos são sobre os Anos Iniciais ( $1^{\circ}$ ao $5^{\circ}$ ano), 14 dedicam-se aos Anos Finais ( $6^{\circ}$ ao $9^{\circ}$ ano) e um volta-se para os dois níveis.

Em relação à revista Investigações em Ensino de Ciências (IENCI) não foi localizado artigo que se dedicasse especificamente às fases da Lua de forma central. Encontramos apenas um trabalho (PAULA; LIMA, 2010) em que o tema aparece abordado entre outras questões.

$\mathrm{Na}$ análise da revista Ensaio: Pesquisa em Educação em Ciências não encontramos trabalho relacionado às fases da Lua de forma central. Verificamos apenas um artigo que inclui o tema entre outros, que foi o de Bretones e Compiani (2010).

$\mathrm{Na}$ revista Experiências em Ensino de Ciências (EENCI) também não há trabalho direcionado especificamente para Lua e suas fases. Existe um estudo que menciona essa temática apenas de forma indireta, o de Darroz e Santos (2012), que trabalha o tema na formação de professores com o uso de bola de isopor, projeção de luz e vídeos.

Por fim, verificamos as edições da revista Alexandria. Constatamos a existência de apenas um trabalho que aborda o tema Lua e suas fases de forma central (BRETONES; COMPIANI, 2014). 
No intuito de fazer uma síntese sobre a presença de conteúdos da Lua e suas fases em artigos publicados em periódicos, organizamos a Tabela 3, relacionando o Nível escolar de abordagem e o Foco temático. As porcentagens indicadas nessa tabela foram calculadas tomando como referência o número de artigos encontrados sobre Lua e suas fases no referido Nível Escolar e ao total geral (52). Alguns trabalhos compreenderam mais de um nível escolar e, por esse motivo, a soma ultrapassa o número de publicações, o que acontece também com o Foco temático.

Tabela 3 - Distribuição de trabalhos sobre Lua e suas fases em artigos de periódicos selecionados por Nível Escolar e Foco Temático

\begin{tabular}{|c|c|c|c|c|}
\hline Nível (N - \%) & Foco & N. & \% nível & $\%$ total \\
\hline El (0-0) & - & - & - & - \\
\hline \multirow[t]{4}{*}{ EF (20-38,4\%) } & Conteúdo e método & 6 & 30 & 11,5 \\
\hline & Formação de professores & 6 & 30 & 11,5 \\
\hline & Características do aluno & 4 & 20 & 7,7 \\
\hline & Características do professor & 4 & 20 & 7,7 \\
\hline \multirow[t]{4}{*}{ EM $(11-21,1 \%)$} & Características do aluno & 5 & 45 & 9,6 \\
\hline & Conteúdo e método & 3 & 27,3 & 5,7 \\
\hline & Formação de professores & 2 & 18,2 & 3,8 \\
\hline & Currículos e programas & 1 & 9,1 & 1,9 \\
\hline \multirow[t]{5}{*}{ ES (11-21,1\%) } & Formação de professores & 5 & 45 & 9,6 \\
\hline & Características do aluno & 2 & 18,2 & 3,8 \\
\hline & Características do professor & 2 & 18,2 & 3,8 \\
\hline & Recursos didáticos & 1 & 9,1 & 1,9 \\
\hline & Conteúdo e método & 1 & 9,1 & 1,9 \\
\hline \multirow[t]{6}{*}{ G (21-40,4\%) } & Conteúdos específicos & 10 & 47,6 & 19,2 \\
\hline & Recursos didáticos & 5 & 23,8 & 9,6 \\
\hline & Conteúdo e método & 3 & 14,3 & 5,7 \\
\hline & Características do aluno & 2 & 9,5 & 3,8 \\
\hline & Características do professor & 1 & 4,7 & 1,9 \\
\hline & Outros & 1 & 4,7 & 1,9 \\
\hline
\end{tabular}

Fonte: elaborada pelos autores.

Em relação ao Nível escolar, os mais abordados nos artigos analisados foram a categoria Geral, que totalizou 21 textos (40,4\%), o Ensino Fundamental, com 20 das produções (38,4\%), e o Ensino Médio e o Superior, que contêm a mesma quantidade de artigos, ou seja, 11 textos $(21,1 \%)$. Não encontramos trabalhos dedicados à Educação Infantil nesses periódicos, o que não significa que não existam trabalhos nessa área, uma vez que publicações para esse nível escolar geralmente se concentram em revistas específicas de educação.

Em relação ao Ensino Fundamental, cujo total de textos é $20(38,4 \%)$, cinco artigos são sobre os Anos Iniciais ( $1^{\circ}$ ao $5^{\circ}$ ano), 14 dedicam-se aos Anos Finais ( $6^{\circ}$ ao $9^{\circ}$ ano) e um volta-se para os dois níveis.

No Ensino Fundamental notamos uma preocupação maior sobre as maneiras de ensinar tais conteúdos. No Ensino Médio há uma tendência a investigar sobre os conhecimentos dos alunos. No Ensino Superior prioriza-se a formação de professores. Já no Geral a preocupação é discutir conteúdos específicos. Neste último averiguamos, como já mencionado anteriormente, uma lacuna na menção dos autores quanto ao nível escolar ao qual se dirige o artigo. 
Para analisar os Focos Temáticos de forma global em relação ao total de artigos, a Tabela 4 exibe as tendências predominantes.

Tabela 4 - Distribuição dos artigos sobre Lua e suas fases po
\begin{tabular}{l|r|r}
\hline Foco & N. & $\%$ \\
\hline Conteúdo e Método & 12 & 23 \\
Características do aluno & 11 & 21,1 \\
Conteúdo Específico & 10 & 19,2 \\
Formação de professores & 7 & 13,4 \\
Recursos didáticos & 6 & 11,5 \\
Características do professor & 5 & 9,6 \\
Currículos e Programas & 1 & 1,9 \\
Outros (Estado da Arte) & 1 & 1,9 \\
\hline
\end{tabular}

Fonte: elaborado pelos autores.

É possível verificar, a partir da Tabela 4, que a maior parte dos trabalhos (23\%) é dedicada a Conteúdo e Método, totalizando 12 textos. Em seguida, temos: Características do Aluno, que tem 11 das produções (21,1\%); Conteúdo Específico, com 10 dos materiais (19,2\%); Formação de Professores, que é a base de 7 dos estudos (13,4\%); Recursos Didáticos, que são o centro de 6 textos (11,5\%); e Características do Professor, que constitui a base de 5 das pesquisas (9,6\%). Por fim, com a mesma quantidade de artigos, estão os focos Currículos e Programas e Outros, cada um deles tem uma investigação (1,9\%).

Dos 12 artigos relacionados a Conteúdo e Método, apenas um se destina aos Anos Iniciais (MORETT; SOUZA, 2010) e utiliza slides e experimentos de baixo custo. Além desse, outros quatro trabalhos utilizam modelos com materiais de baixo custo, como bola de isopor (DARROZ; HEINECK; PEREZ, 2011; DARROZ et al., 2012; MARTINS; LANGHI, 2012). Cinco dos trabalhos fazem ou propõem a observação da Lua no céu de alguma maneira (BRETONES; COMPIANI, 2010; DARROZ et al., 2012; JAFELICE, 2015; LONGHINI; GOMIDE, 2014; MOTA; BONOMINO; ROSADO, 2009). Outros sugerem a representação do sistema com o corpo dos alunos (GIOVANNINI; PELLENZ; CATELLI, 2014), o uso de mapa conceitual (SILVEIRA; MENDONÇA, 2015), a história em quadrinhos (MARTINS; LANGHI, 2012), a história da Astronomia (MOTA; BONOMINI; ROSADO, 2009) e a aplicação de questionário (PAULA; LIMA, 2010). Por fim, Kriner (2004) faz uma discussão mais geral sobre o que ensinar sobre esse tema e quando introduzi-lo.

Os 11 artigos com foco nas Características do Aluno tratam de questões diversas. Foram encontradas investigações sobre concepções iniciais, avaliações diagnósticas para verificar concepções, evolução conceitual e compreensão de conceitos de forma geral.

Vale a pena mencionar outro foco com grande quantidade de trabalhos: Conteúdo Específico (10). Essa categoria não aparece em teses e dissertações, mas representa 19,2\% do total de artigos analisados, localizados em periódicos de ensino de Física especificamente.

Em relação aos seis artigos sobre Recursos Didáticos, três trabalhos abordam o uso de tecnologias computacionais, como hipermídia e software (FAGUNDES; SILVA; BARROSO, 2015; LONGHINI; MENEZES, 2010; SILVA, 2009). Dois indicam o uso de materiais de baixo custo como bola de isopor (CANALLE, 1999; SARAIVA et al., 2007). Por fim, há a menção aos brinquedos de parque/praça (CAMINO, 2012). 
O que ressalta num olhar mais geral para tal produção é que, entre os artigos publicados em periódicos, a maior parte trata de metodologias de ensino voltadas ao Ensino Fundamental, ou seja, o Nível Escolar em que mais aparecem conteúdos sobre a Lua nos currículos e nos programas escolares. Também é evidenciado um grande número de artigos publicados sem menção específica ao nível a que se dirige, especialmente na RBEF e na CBEF. Um olhar mais geral ainda indica que tais publicações se dirigem, pretendem e são publicadas visando suprir temas pouco explorados na formação dos professores ou em sua própria prática, tanto em conteúdos quanto em metodologias de ensino.

Nessa seleção de artigos analisados, ainda há a tendência para trabalhos relacionados ao Sistema Sol-Terra-Lua na perspectiva espacial e para questões mais práticas do processo de ensino e aprendizagem. Porém, encontramos um trabalho aprofundado no aspecto didático desse ensino. Também percebemos, no conjunto de artigos, uma maior preocupação com os processos de pensamento dos estudantes, uma vez que a quantidade de trabalhos com o foco Características do Aluno foi expressivo.

\section{Trabalhos apresentados em eventos}

Os eventos considerados relevantes para este trabalho e selecionados para análise de suas Atas, Anais e Boletins estão organizados no Quadro 3. A identificação dos trabalhos está no Anexo C.

Quadro 3 - Eventos analisados e período abrangido

\begin{tabular}{|l|l|c|}
\hline \multicolumn{1}{|c|}{ Evento } & \multicolumn{1}{|c|}{$\begin{array}{c}\text { Período (edição e } \\
\text { ano) }\end{array}$} & $\begin{array}{c}\text { No Trabalhos sobre } \\
\text { o Tema }\end{array}$ \\
\hline Simpósio Nacional de Ensino de Física (SNEF) & I (1970) ao XXI (2015) & 13 \\
\hline Simpósio Nacional de Educação em Astronomia (SNEA) & I (2011) ao III (2014) & 6 \\
\hline Reunião Anual da Sociedade Astronômica Brasileira (RASAB) & I (1974) ao XXXIX (2015) & 3 \\
\hline Encontro Nacional em Pesquisa em Educação em Ciências (ENPEC) & I (1997) ao X (2015) & 32 \\
\hline \multicolumn{2}{|c|}{ Totais } & 32 \\
\hline
\end{tabular}

Fonte: elaborado pelos autores.

Essa seleção de trabalhos apresentados em eventos buscou apenas produções relacionadas de forma direta ao ensino relacionado da Lua e suas fases. Foram encontrados 29 textos ao todo. Primeiro, foram divididos por Nível Escolar. Oito dedicam-se ao Ensino Fundamental, totalizando $27,6 \%$ dos materiais. Destes, quatro $(13,8 \%)$ tratam desse nível de forma geral, um $(3,4 \%)$ é específico para os Anos Iniciais, e três (10,3\%) discorrem sobre os Anos Finais. Os trabalhos sobre o Ensino Médio totalizam dez (34,5\%), com cinco (17,2\%) produções voltadas para o Ensino Superior, sete $(24,1 \%)$ na categoria Geral, e um $(3,4 \%)$ na característica Não-escolar. 
Tabela 5 - Distribuição dos trabalhos apresentados em eventos sobre Lua e suas fases por Nível Escolar e Foco Temático

\begin{tabular}{ll|r|r|r}
\hline Nível (N - \%) & Foco & N. & \% nível & \% total \\
\hline El (0-0) & \multicolumn{1}{c}{-} & - & - & - \\
EF (8-27,6\%) & Conteúdo e método & 5 & 62,5 & 17,2 \\
& Características do Aluno & 2 & 25 & 6,9 \\
& Recursos Didáticos & 1 & 12,5 & 3,4 \\
EM (10-34,5\%) & Conteúdo e Método & 8 & 80 & 27,6 \\
\multirow{2}{*}{ ES (5-17,2\%) } & Características do Aluno & 2 & 20 & 6,9 \\
& Recursos Didáticos & 2 & 40 & 6,9 \\
& Características do aluno & 2 & 40 & 6,9 \\
G (7-24,1\%) & Conteúdo e Método & 1 & 20 & 3,4 \\
& Recursos Didáticos & 3 & 42,8 & 10,3 \\
& Conteúdo e Método & 2 & 28,6 & 6,9 \\
& Conteúdos Específicos & 1 & 14,3 & 3,4 \\
Não escolar (1-3,4\%) & Recursos Didáticos & 1 & 14,3 & 3,4 \\
\hline
\end{tabular}

Fonte: elaborada pelos autores.

De acordo com a Tabela 5, podemos identificar que Conteúdo e Método é um foco majoritário no Ensino Médio e Fundamental, o que não ocorre no Ensino Superior e na denominação Geral. Também é importante notar que o Nível Escolar Geral aparece de forma considerável entre as atas de eventos, assim como entre os artigos, mas não nas teses e nas dissertações.

No que diz respeito apenas ao Foco Temático dos trabalhos apresentado em eventos, desenvolvemos a Tabela 6 .

Tabela 6 - Distribuição de trabalhos apresentados em eventos sobre Lua e suas fases por Foco Temático

\begin{tabular}{l|r|r}
\hline Foco & N. & \% \\
\hline Conteúdo e Método & 14 & 48,3 \\
Recursos Didáticos & 7 & 24,1 \\
Características do Aluno & 6 & 20,7 \\
Conteúdo Específico & 1 & 3,4 \\
Formação de Conceitos & 1 & 3,4 \\
\hline
\end{tabular}

Fonte: elaborado pelos autores.

Em relação ao Foco Temático é possível observar que é predominante a preocupação em torno do Conteúdo e Método, presente em 14 textos (48,3\%). Em seguida, está a discussão sobre Recursos Didáticos, visível em sete estudos (24,1\%). Depois, temos as Características do Aluno, notadas em seis publicações $(20,7 \%)$, e os de menor ocorrência são o Conteúdo Específico, com um trabalho (3,4\%), e a Formação de Conceitos, que também é representada em apenas um texto $(3,4 \%)$.

Dos 14 trabalhos que estão categorizados em Conteúdo e Método, cinco propõem alguma forma de observação da Lua no céu, entre outras metodologias, para o Ensino Fundamental de forma geral, como o caso de Santos, Pereira e Penido (2011); os Anos Finais, como vemos em Pellenz e Giovannini (2014); o Ensino Fundamental e o Médio, presente em Romano, Trevisan e Lattari (1999) e o Ensino Médio, enfocado nos estudos de 
Martins e Langhi (2011) e de Santiago e Pacca (2015). Quatro sugerem o uso de materiais de baixo custo, como bolas, areia, pedras, cal etc. (SANTIAGO; PACCA, 2015; SANTOS; PEREIRA; PENIDO, 2011; SELAU et al., 2012; SOARES; BRAGA, 2007;). Três apresentam recursos táteis voltados para o ensino de alunos com deficiência visual (CAMARGO; BARROS; GOMES, 2014; CAMARGO et al., 2015; STEFFANI; ZANATTA, 2011). Outros propõem o uso do corpo (TREVISAN et al., 1993), história em quadrinhos (MARTINS; LANGHI, 2011), poesia (SAMPAIO; SANTOS, 2011) e a utilização de sextante (CARVALHO NETO et al., 2015). Ainda sobre o foco Conteúdo e Método, apenas o trabalho de Selau et al. (2012) foi desenvolvido especificamente para os Anos Iniciais do Ensino Fundamental.

Em relação aos Recursos Didáticos, dois textos sugerem a construção de modelos com materiais de baixo custo (LIMA; SILVA, 2012; MARQUES; SILVA; FURTADO, 2002). Um indica o uso de um modelo tátil para alunos com deficiência visual (COZENDEY; PESSANHA, 2011). Há um que discorre sobre um modelo didático (VALÉRIO; CORREA, 2015). Existe também um trabalho que sugere kits para professores dos Anos Iniciais (NOGUEIRA, 2015), história em quadrinhos (SOARES NETO; FURTADO, 2009). Por fim, um estudo debate a presença de recursos computacionais (FAGUNDES; BARROSO; SILVA, 2013).

Não podemos deixar de mencionar os trabalhos relacionados às Características do Aluno. Eles dedicam-se às concepções dos estudantes abrangendo o Ensino Fundamental, o Médio e o Superior.

Percebemos uma questão similar à das bases analisadas anteriormente. Os trabalhos, em sua maioria, abordam o ensino na relação espacial dos fenômenos, priorizando, nas discussões, propostas didáticas para a prática docente.

\section{Considerações Finais}

No que diz respeito às análises dos diferentes materiais, encontramos um número expressivo de trabalhos que abordam o tema Lua. Desse modo, confirmamos a tendência apresentada por outros autores, de que esse é um dos assuntos mais tratados (BRETONES; JAFELICE; HORVATH, 2016; BRETONES; MEGID NETO, 2011; BRETONES; ORTELAN, 2012; LELLIOTT; ROLLNICK, 2010).

Entre os 123 trabalhos analisados, o Nível Escolar mais pesquisado é o Ensino Fundamental, totalizando 55 dos textos (44,7\%), em especial os Anos Finais dessa etapa. Poucos trabalhos são dedicados aos Anos Iniciais, especialmente em artigos e trabalhos apresentados em eventos. Essa presença considerável desse nível de ensino pode estar relacionada aos documentos oficiais nacionais, que geralmente abordam o tema fases da Lua e eclipses nesse período. Após o Ensino Fundamental, o nível que se destaca é o Ensino Médio, com 37 ocorrências (30\%), seguido do Geral, que está em 29 textos (23,6\%); apenas depois desponta o Ensino Superior, com 25 produções (20,3\%). Temos ainda um trabalho relacionado à educação Não-Escolar. Ademais, neste levantamento, não foram localizados nas bases e no período analisado trabalhos dedicados ao tema Lua na Educação Infantil.

Em relação ao Foco Temático, os textos analisados expressam uma preocupação com a formação do professor e suas formas de ensinar. Isso é evidenciado pelos focos mais abordados, em especial Conteúdo e Método, que é visto em 37 das publicações (30,1\%) e se destaca nos diferentes tipos de materiais analisados, seguido por Recursos Didáticos, notado em 22 textos (17,9\%). 
Os focos que aparecem na sequência são: Características do Aluno, com 19 materiais (15,4\%); Formação de Professores, com 18 estudos (14,6\%); Características do Professor, com 11 produções (8,9\%); e Conteúdo Específico, com 11 ocorrências (8,9\%). Essa constatação mostra uma lacuna referente a estudos sobre Currículos e Programas, categoria que é averiguada em apenas 3 dos textos (2,4\%), e Formação de Conceitos, eixo que também integra somente 3 pesquisas (2,4\%), entre outras possibilidades não categorizadas nesta pesquisa. Encontramos ainda um trabalho dedicado ao Estado da Arte, inserido no eixo Outros.

Como resultado geral, em relação ao foco Conteúdo e Método, temos propostas de metodologias de ensino variadas. Elas sugerem: a construção de modelos com materiais de baixo custo, a observação, as aulas expositivas com vídeos ou slides, os experimentos, o uso de tecnologias computacionais, como simuladores e softwares, a construção de materiais táteis para alunos com deficiência visual, a visita a planetário, a representação do Sistema Sol-Terra-Lua com o corpo dos alunos, a utilização de mapa conceitual, a abordagem com história em quadrinhos, uso da história da Astronomia, de poesia, o emprego de sextante e, por fim, um trabalho voltado para a discussão mais geral sobre o tema, englobando o que e como ensinar.

Por sua vez, os Recursos Didáticos encontrados também são diversos. Eles incluem tecnologias computacionais, tais como hipermídia e softwares; kits e/ou manuais; corpo dos alunos; materiais de baixo custo para o modelo do sistema Sol-Terra-Lua; materiais táteis para o ensino de alunos com deficiência visual; modelos didáticos; brinquedos de parque/ praça; história em quadrinhos; e um dos trabalhos inclui a observação da Lua.

Os recursos e metodologias elencados se relacionam com muitas formas de modelização utilizando materiais de baixo custo, bolas de isopor, tecnologias computacionais, uso do corpo, mas também encontramos algumas propostas de inclusão da observação.

Contudo, fazendo uma análise mais apurada, notamos que pouco há contemplado que privilegie a observação da Lua no céu, mesmo com a grande incidência de trabalhos para o Ensino Fundamental, o que poderia provocar a preocupação dos pesquisadores em buscar relações com o ambiente imediato dos estudantes. Na maioria dos trabalhos em que a observação aparece, seu uso é pontual e bastante passageiro. Sobre propostas que buscam a dimensão da observação da Lua no céu no referencial topocêntrico, vemos Lima (2006), Jafelice (2015) e Pellenz (2015), e ainda, fora do período de análise que trata especificamente do tema, Simon (2016).

Outra possibilidade que aparece em poucos trabalhos é o desenvolvimento interdisciplinar, cultural, filosófico e poético que pode ser desenvolvido a partir da temática Lua. Também é possível verificar que poucas produções utilizam a História da Ciência como recurso para o ensino desse tema. Isso mostra claramente que, embora a produção revele que muito está disponível para pesquisadores, práticos e professores, muito ainda pode por ser feito no que se refere à pesquisa da área.

Uma forma de entender ou propor o ensino de conteúdos de Ciências Naturais ou de Astronomia, em particular, é privilegiar, nos Anos Iniciais do Ensino Fundamental, as vivências e as experiências cotidianas com relação ao ambiente, à natureza e a seus fenômenos. Nos anos seguintes, seria importante utilizar as vivências anteriores e destacar as explicações e o uso de modelos das mais variadas formas. Após isso, no Ensino Médio, poderiam ser levados em conta tais aprendizados anteriores e inserir elementos de gravitação, entre outros, como se propõe nos programas escolares. 
A observação da Lua é bastante acessível e pouco explorada. Isso pode evidenciar uma priorização do ensino na escala do sistema Sol-Terra-Lua, sem incluir a perspectiva do observador ou verificar se o estudante ou o professor possuem essa vivência e compreensão. Mesmo no ensino em sala de aula, sabendo que a observação da Lua requer horários e ambientes fora do contexto escolar, o estímulo a tal prática é pouco explorado, mas é possível, conforme mostram algumas das referências citadas.

Compiani (2012) destaca que há uma predominância no espaço escolar da valorização das representações e dos conceitos, alimentando a separação entre mundo teórico e mundo vivido. As cognições mais complexas, "[...] pelo menos uma boa parte delas, não deveriam perder suas relações de contexto espaço-temporal de origem e nem adquirir essa ideia de explicação única." (COMPIANI, 2012, p. 133).

A maneira como tem sido priorizado o ensino e uma grande parte das pesquisas desenvolvidas na área parece manter o foco em apenas uma das escalas e das dimensões dos fenômenos, sem favorecer a compreensão da espacialidade dos eventos pelos estudantes e pelos professores, o que é um desafio indicado por diversos autores (BISCH, 1998; LEITE, 2002, 2006). Esse distanciamento não favorece a contextualização da construção desse conhecimento, podendo provocar certa fragmentação da compreensão por parte de quem aprende. Não é de surpreender certos argumentos que aparecem em muitos dos trabalhos citados e consultados de que esse ainda não é um tema bem compreendido por professores e estudantes.

Bisch (1998, p. 124) expõe em seu trabalho a importância da sensibilização para o contato direto com a natureza como "[...] ponto de referência essencial para a construção de conhecimentos". Combate, assim, o "[...] absurdo de um ensino livresco, teórico" e dissociado da realidade. Para ele,

[...] uma Astronomia 'de gabinete' pode ser justificada no caso de um astrônomprofissional, experiente, adulto, porém julgamos que uma Astronomia livresca, desembelezada, de sala de aula, é completamente fora de propósito no ensino fundamental, onde uma das atitudes mais importantes a exercitar nos alunos é a sua capacidade de observação da natureza, onde é essencial sensibilizá-los com relação à beleza e diversidade do universo, instigar sua curiosidade e imaginação. (BISCH, 1998, p. 125).

Apesar de o autor se direcionar especificamente para professores do Ensino Fundamental, essa questão permeia toda a educação básica. É importante, nesse sentido, que o raciocínio não interponha uma distância com a percepção direta, a base do pensamento comum, mas que as diferentes escalas e dimensões possam ser utilizadas e exploradas de forma mais consciente, entendendo que o conhecimento é complexo.

Essa preocupação com o ensino desse tema ao longo dos anos poderia ser discutida e pesquisada em trabalhos voltados para o Foco Temático Currículos e Programas. Todavia, como verificamos, esse é o centro de poucos trabalhos. Também possivelmente contribuiriam com essas questões pesquisas voltadas para a Formação de Conceitos.

Cabe também a reflexão sobre como estamos desenvolvendo esses processos com os estudantes e os professores. Precisamos pensar se as pesquisas não estão seguindo o que Pasachoff (2001) critica, ou seja, se elas estão reproduzindo mais do mesmo, sem muitos avanços em termos didáticos de sua discussão. 
Ainda acrescentamos que em níveis pragmáticos, com poucas reflexões em torno das formas de pensar do estudante, do professor e da formação dos conceitos.

Destacamos que, apesar de o tema Lua, incluindo suas fases, parece muito abordado no ensino e discutido em demasia nas pesquisas, os resultados obtidos mostram que existem Focos Temáticos e Níveis Escolares que não foram contemplados em pesquisas no período e nas bases analisadas, podendo ser abordados em futuras investigações. Para o avanço da área, é fundamental, tanto para pesquisadores quanto para professores, conhecer as pesquisas desenvolvidas, seus caminhos e seus descaminhos.

\section{Referências}

BARDIN, L. Análise de conteúdo. São Paulo: Edições 70, 2011.

BARNETT, M.; MORRAN, J. Adressing children's alternative frameworks of the moon's phases and eclipses. International Journal of Science Education, London, v. 24, n. 8, p. 859-879, 2002.

BAXTER, J. Children's understanding of familiar astronomical events. International Journal of Science Education, London, v. 11, n. 5, p. 502-513, 1989.

BAXTER, J. The influences of the national curriculum on children's misconceptions about astronomy and the use of these misconceptions in the development of interactive teaching materials. In: GOUGUENHEIM, L.; MCNALLY, D; PERCY, J. R. (org.). New trends in astronomy teaching: IAU colloquium 162. Cambridge: Cambridge University Press, 1998. p. 139-146.

BISCH, S. M. Astronomia no ensino fundamental: natureza e conteúdo do conhecimento de estudantes e professores. 1998. 310 f. Tese (Doutorado em Educação) - Faculdade de Educação, Universidade de São Paulo, São Paulo, 1998.

BRETONES, P. S.; MEGID NETO, J. An analysis of papers on astronomy education in proceedings of IAU meetings from 1988 to 2006. Astronomy Education Review, Washington, v. 10, n. 1, p. 1-9, 2011.

BRETONES, P. S.; MEGID NETO, J. Tendências de teses e dissertações sobre educação em astronomia no Brasil. Boletim da Sociedade Astronômica Brasileira, São Paulo, v. 24, n. 2, p. 35-43, 2005.

BRETONES, P. S.; ORTELAN, G. B. Temas e conteúdos abordados em teses e dissertações sobre educação em astronomia no Brasil. In: SIMPÓSIO NACIONAL DE EDUCAÇÃO EM ASTRONOMIA, 2., 2012, São Paulo. Anais [...]. São Paulo: IF:USP, 2012. v. 2, p. 651-660.

BRETONES, P. S.; JAFELICE, L. C.; HORVATH, J. E. Ten years of "Latin-American Journal of Astronomy Education" RELEA: achievements and challenges for international astronomy education

development. Journal of Astronomy \& Earth Sciences Education, Littleton, v. 3, n. 2, p. 111-124, 2016.

BRETONES, P. S.; MEGID NETO, J. CANALLE, J. B. G. A educação em astronomia nos trabalhos das reuniões anuais da Sociedade Astronômica Brasileira. Boletim da Sociedade Astronômica Brasileira, São Paulo, v. 26, n. 2, p. 55-72, 2006.

BUSSI, B.; BRETONES, P. S. Educação em astronomia nos trabalhos dos ENPECs de 1997 a 2011. In: ENCONTRO NACIONAL DE PESQUISA EM EDUCAÇÃO EM CIÊNCIAS, 9., 2013, Águas de Lindóia. Anais [...]. Rio de Janeiro: Abrapec, 2013. p. 1-8.

CAMINO, N. Ideas previas y cambio conceptual em astronomía: un estudio con maestros de primaria sobre el día y la noche, las estaciones y las fases de la luna. Enseñanza de las Ciencias, Barcelona, v. 13, n.1, p. 81-96, 1995. 
COMPIANI, M. O desprestígio das imagens no ensino de ciências, até quando?: uma contribuição das geociências com a gestalt. Alexandria, Florianópolis, v. 5, n. 1, p. 127-154, 2012.

FANETTI, T. M. The relationships of scale concepts on college age students' misconceptions about the cause of the lunar phases. 2001. 103 f. Thesis (Master of Science) - lowa State University, Ames, 2001.

FERNANDES, T. C. D.; NARDI, R. Uma análise dos trabalhos sobre educação em astronomia nos encontros nacionais de pesquisa em educação em ciências. In: ENCONTRO NACIONAL DE PESQUISA EM EDUCAÇÃO EM CIÊNCIAS, 9., 2015, Águas de Lindóia. Anais [...]. Rio de Janeiro: Abrapec, 2015.

IACHEL, G.; NARDI, R. Algumas tendências das publicações relacionadas à astronomia em periódicos brasileiros de ensino de física nas últimas décadas. Ensaio, Belo Horizonte, v. 12, n. 2, p. 225-238, 2010.

LEITE, C. Formação do professor de ciências em astronomia: uma proposta com enfoque na espacialidade. 2006. 274 f. Tese (Doutorado em Educação) - Faculdade de Educação, Universidade de São Paulo, São Paulo, 2006.

LEITE, C. Os professores de ciências e suas formas de pensar a astronomia. 2002. 165 f. Dissertação (Mestrado em Ensino de Ciências) - Universidade de São Paulo, São Paulo, 2002.

LELLIOTT, A.; ROLLNICK, M. Big ideas: a review of astronomy education research 1974-2008. International Journal of Science Education, London, v. 32, n. 13, p. 1771-1799, 2010.

LIGHTMAN, A.; SADLER, P. Teacher predictions versus actual student gains. The Physics Teacher, New York, v. 31, n. 3, p. 162-167, 1993.

LINDELL, R. S.; OLSEN, J. P. Developing the lunar phases concept inventory. In: PHYSICS EDUCATION RESEARCH CONFERENCE, 2002, Boise, USA. Proceedings [...]. Boise, Idaho: PER Central, 2002. p. 1-4.

MARRONE JUNIOR, J.; TREVISAN, R. H. Um perfil da pesquisa em ensino de astronomia no Brasil a partir da análise de periódicos de ensino de ciências. Caderno Brasileiro de Ensino de Física, Florianópolis, v. 26, n. 3, p. 547-574, 2009

MEGID NETO, J. Tendências da pesquisa acadêmica sobre o ensino de ciências no nível fundamental. 1999. 114 f. Tese (Doutorado em Educação) - Faculdade de Educação, Universidade Estadual de Campinas, Campinas, 1999.

NAVARRO, A. V. Tenerife tiene seguro de sol (y de luna): representaciones del profesorado de primaria acerca del día y la noche. Enseñanza de las Ciencias, Barcelona, v. 19, n. 1, p. 31-44, 2001.

ORTELAN, G. B.; BRETONES, P. S. Educação em astronomia nos trabalhos das reuniões anuais da SAB entre 2004 e 2010. Boletim da Sociedade Astronômica Brasileira, São Paulo, v. 37, p. 76, 2012.

PASACHOFF, J. M. What should college students learn?: phases and seasons? is less more or is less less? Astronomy Education Review, Washington, v. 1, n. 1, p. 124- 130, 2001.

QUÍLEZ, G.; PEÑA, M. J. M.; BEGOÑA, M. El modelo sol-tierra-luna en el lenguaje iconográfico de estudiantes de magisterio. Enseñanza de las Ciencias, Barcelona, v. 25, n. 2, p. 153-166, 2005.

SCHOON, K. J. Student's alternative conceptions of earth and space. Journal of Geological Education, London, v. 40, n. 3, p. 209-214, 1992.

SIMON, P. C. S. G. Ensino de astronomia para os anos iniciais: uma proposta a partir da observação da lua. 2016. 209 f. Dissertação (Mestrado em Educação) - Universidade Federal de São Carlos, São Carlos, 2016. 
STAHLY, L. L.; KROCKOVER, G. H.; SHEPARDSON, D. P. Third grade students' ideas about the lunar phases. Journal of Research in Science Teaching, London, v. 36, n. 2, p. 159-177, 1999.

TRUMPER, R. University students' conceptions of basic astronomy concepts. Physics Education, Bristol, v. 35, n. 1, p. 9-15, 2000.

TRUNDLE, K. C.; ATWOOD, R. K.; CHRISTOPHER, J. E. Preservice elementary teachers conceptions of moon phases before and after instruction. Journal of Research in Science Teaching, London, v. 39, n. 7, p. 633-658, 2002.

ZEILIK, M.; SCHAU, C.; MATTERN, N. Misconceptions and their change in university-level astronomy courses. The Physics Teacher, New York, v. 36, p. 104-107, 1998.

\section{Anexo A - Teses e dissertações analisadas}

\begin{tabular}{|c|c|c|c|c|}
\hline Autor(a) & Título & Referência & Nível escolar & Foco \\
\hline AMARAL, D. S. & $\begin{array}{l}\text { Estudo de uma sequência didática na pers- } \\
\text { pectiva de Ausubel para alunos do sexto ano } \\
\text { do Ensino Fundamental sobre astronomia }\end{array}$ & $\begin{array}{l}\text { Dissertação (Mestrado em Ensino } \\
\text { de Física) - Universidade Federal } \\
\text { de Santa Maria, Santa Maria, } 2015 .\end{array}$ & EF2 & $\begin{array}{l}\text { Conteúdo e } \\
\text { método }\end{array}$ \\
\hline AMARAL, P. & $\begin{array}{l}\text { O ensino de astronomia nas séries finais do } \\
\text { ensino fundamental: uma proposta de mate- } \\
\text { rial didático de apoio ao professor }\end{array}$ & $\begin{array}{l}\text { Dissertação (Mestrado em Ensino } \\
\text { de Ciências) - Universidade de Bra- } \\
\text { sília, Brasília, } 2008 .\end{array}$ & EF2 & $\begin{array}{l}\text { Recursos } \\
\text { didáticos }\end{array}$ \\
\hline BARTELMEBS, R. C. & $\begin{array}{l}\text { O ensino de astronomia nos anos iniciais: } \\
\text { reflexões produzidas em uma comunidade } \\
\text { de prática }\end{array}$ & $\begin{array}{l}\text { Dissertação (Mestrado em Educa- } \\
\text { ção em Ciências) - Universidade } \\
\text { Federal do Rio Grande, Rio Grande, } \\
2012 .\end{array}$ & EF1 & $\begin{array}{l}\text { Formação de } \\
\text { professores }\end{array}$ \\
\hline BERALDO, T. M. L. & $\begin{array}{l}\text { O ensino de conceitos relacionados com a } \\
\text { Terra no espaço, nas séries iniciais do ensi- } \\
\text { no fundamental: elementos para reflexão em } \\
\text { torno da formação docente }\end{array}$ & $\begin{array}{l}\text { Dissertação (Mestrado em Edu- } \\
\text { cação) - Universidade Federal de } \\
\text { Mato Grosso, Cuiabá, } 1998 .\end{array}$ & EF1 & $\begin{array}{l}\text { Características } \\
\text { de professor e } \\
\text { aluno }\end{array}$ \\
\hline BERNARDES, A. 0. & $\begin{array}{l}\text { Astronomia inclusiva no universo da defici- } \\
\text { ência visual }\end{array}$ & $\begin{array}{l}\text { Dissertação (Mestrado em Ciências } \\
\text { Naturais) - Universidade Estadual } \\
\text { do Norte Fluminense, Campos dos } \\
\text { Goyatacazes, } 2009 .\end{array}$ & EF1, EF2, EM & $\begin{array}{l}\text { Recursos } \\
\text { didáticos }\end{array}$ \\
\hline BISCH, S. M. & $\begin{array}{l}\text { Astronomia no ensino fundamental: natureza } \\
\text { e conteúdo do conhecimento de estudantes } \\
\text { e professores }\end{array}$ & $\begin{array}{l}\text { Tese (Doutorado em Educação) } \\
\text { - Faculdade de Educação, Univer- } \\
\text { sidade de São Paulo, São Paulo, } \\
\text { 1998. }\end{array}$ & $E F, E S$ & $\begin{array}{l}\text { Características } \\
\text { de professor e } \\
\text { aluno }\end{array}$ \\
\hline BRETONES, P. S. & $\begin{array}{l}\text { A astronomia na formação continuada de pro- } \\
\text { fessores e o papel da racionalidade prática } \\
\text { para o tema da observação do céu }\end{array}$ & $\begin{array}{l}\text { Tese (Doutorado em Ciências) - Insti- } \\
\text { tuto de Geociências, Universidade Es- } \\
\text { tadual de Campinas, Campinas, } 2006 .\end{array}$ & EF2, ES & $\begin{array}{l}\text { Formação de } \\
\text { professores }\end{array}$ \\
\hline CAETANO, A. A & $\begin{array}{l}\text { O uso de modelos e aparelhos no ensino de } \\
\text { astronomia para as séries iniciais do ensino bá- } \\
\text { sico: instrumentos mediadores do aprendizado }\end{array}$ & $\begin{array}{l}\text { Dissertação (Mestrado em Educação) } \\
\text { - Universidade Federal de Minas Ge- } \\
\text { rais, Belo Horizonte, } 2007 .\end{array}$ & EF1 & $\begin{array}{l}\text { Recursos } \\
\text { didáticos }\end{array}$ \\
\hline CAMPOS, J. A. S. & $\begin{array}{l}\text { Um estudo exploratório sobre o uso de ambien- } \\
\text { tes virtuais não imersivos em 3D no ensino de } \\
\text { astronomia }\end{array}$ & $\begin{array}{l}\text { Dissertação (Mestrado) - Universida- } \\
\text { de Federal do Rio de Janeiro, Rio de } \\
\text { Janeiro, } 2004 .\end{array}$ & ES & $\begin{array}{l}\text { Recursos } \\
\text { didáticos }\end{array}$ \\
\hline CARRILHO, J. J. S. & $\begin{array}{l}\text { Astronomia no ensino médio: a ciência e o lúdi- } \\
\text { co - desafiando e educando }\end{array}$ & $\begin{array}{l}\text { Dissertação (Mestrado em Ensino de } \\
\text { Astronomia) - Universidade Estadual } \\
\text { de Feira de Santana, Feira de Santa- } \\
\text { na, 2015. }\end{array}$ & EM & $\begin{array}{l}\text { Recursos } \\
\text { didáticos }\end{array}$ \\
\hline DARROZ, L. M & $\begin{array}{l}\text { Uma proposta para trabalhar conceitos de } \\
\text { astronomia com alunos concluintes do curso } \\
\text { de formação de professores da modalidade } \\
\text { normal }\end{array}$ & $\begin{array}{l}\text { Dissertação (Mestrado em Ensino de } \\
\text { Física) - Universidade Federal do Rio } \\
\text { Grande do Sul, Porto Alegre, } 2010 .\end{array}$ & EM & $\begin{array}{l}\text { Formação de } \\
\text { professores }\end{array}$ \\
\hline DEBOM, C. R. & $\begin{array}{l}\text { O aprendizado da astronomia e das ciências } \\
\text { afins com a mediação da observação rudimen- } \\
\text { tar e da imagem astronômica }\end{array}$ & $\begin{array}{l}\text { Dissertação (Mestrado em Ensino de } \\
\text { Física) - Universidade Federal do Rio } \\
\text { Grande do Sul, Porto Alegre, } 2010 .\end{array}$ & EM & $\begin{array}{l}\text { Conteúdo e } \\
\text { método }\end{array}$ \\
\hline
\end{tabular}




\begin{tabular}{|c|c|c|c|c|}
\hline Autor(a) & Título & Referência & Nível escolar & Foco \\
\hline DIAS, M. B. & $\begin{array}{l}\text { Astronomia na educação de jovens e adul- } \\
\text { tos: uma proposta }\end{array}$ & $\begin{array}{l}\text { Dissertação (Mestrado em Ensino de } \\
\text { Física) - Pontifícia } \\
\text { Universidade Católica de Minas Gerais, } \\
\text { Belo Horizonte, } 2010 .\end{array}$ & EM & $\begin{array}{l}\text { Conteúdo e } \\
\text { método }\end{array}$ \\
\hline FAGUNDES, A. L. & $\begin{array}{l}\text { Avaliação de uma hipermídia educacional } \\
\text { sobre fases da lua }\end{array}$ & $\begin{array}{l}\text { Dissertação (Mestrado em Educação } \\
\text { Científica e Tecnológica) - Universida- } \\
\text { de Federal de Santa Catarina, Florianó- } \\
\text { polis, } 2014 .\end{array}$ & ES & $\begin{array}{l}\text { Recursos } \\
\text { didáticos }\end{array}$ \\
\hline FERREIRA, A. B. & $\begin{array}{l}\text { O processo de escolarização de crianças } \\
\text { surdas no ensino fundamental: um olhar } \\
\text { para o ensino de ciências articulado aos } \\
\text { fundamentos da astronomia }\end{array}$ & $\begin{array}{l}\text { Dissertação (Mestrado em Educação } \\
\text { para a Ciência) - Universidade Estadu- } \\
\text { al Paulista, Bauru, } 2015 .\end{array}$ & EF1 & $\begin{array}{l}\text { Formação de } \\
\text { conceitos }\end{array}$ \\
\hline FURTADO, L. M. V. & $\begin{array}{l}\text { O mundo é o lugar: um estudo das repre- } \\
\text { sentações dos professores sobre os fenô- } \\
\text { menos astronômicos }\end{array}$ & $\begin{array}{l}\text { Dissertação (Mestrado em Educação) - } \\
\text { Faculdade de Educação, Universidade } \\
\text { de São Paulo, São Paulo, } 2005 .\end{array}$ & $\mathrm{EF}$ & $\begin{array}{l}\text { Característica de } \\
\text { professor }\end{array}$ \\
\hline GONZAGA, E. P. & $\begin{array}{l}\text { Análise da evolução das concepções astro- } \\
\text { nômicas apresentadas por professores de } \\
\text { algumas escolas estaduais (Mauá, Ribeirão } \\
\text { Pires e Rio Grande da Serra) }\end{array}$ & $\begin{array}{l}\text { Dissertação (Mestrado em Ensino de } \\
\text { Ciências e Matemática) - Universidade } \\
\text { Cruzeiro do Sul, 2009. }\end{array}$ & EF-EM & $\begin{array}{l}\text { Característica de } \\
\text { professor }\end{array}$ \\
\hline GONZATTI, S. E. M. & $\begin{array}{l}\text { Um curso introdutório à astronomia para a } \\
\text { formação inicial de professores de ensino } \\
\text { fundamental, em nível médio }\end{array}$ & $\begin{array}{l}\text { Dissertação (Mestrado em Ensino de } \\
\text { Física) - Universidade Federal do Rio } \\
\text { Grande do Sul, Porto Alegre, } 2008 .\end{array}$ & EM & $\begin{array}{l}\text { Formação de } \\
\text { Professores }\end{array}$ \\
\hline HERZOG, Z. M. & $\begin{array}{l}\text { Ensino de ciências na } 5^{\text {a }} \text { série através de } \\
\text { software educacional: } 0 \text { despertar para a } \\
\text { física }\end{array}$ & $\begin{array}{l}\text { Dissertação (Mestrado em Ensino de } \\
\text { Física) - Universidade Federal do Rio } \\
\text { Grande do Sul, Porto Alegre, 2009. }\end{array}$ & EF2 & $\begin{array}{l}\text { Recursos } \\
\text { didáticos }\end{array}$ \\
\hline IACHEL, G. & $\begin{array}{l}\text { Um estudo exploratório sobre o ensino de } \\
\text { astronomia na formação continuada de pro- } \\
\text { fessores }\end{array}$ & $\begin{array}{l}\text { Dissertação (Mestrado em Educação } \\
\text { para a Ciência) - Universidade Estadu- } \\
\text { al Paulista, Bauru, 2009. }\end{array}$ & EF2, EM & $\begin{array}{l}\text { Formação de } \\
\text { professores }\end{array}$ \\
\hline IACHEL, G. & $\begin{array}{l}\text { Os caminhos da formação de professores e } \\
\text { da pesquisa em ensino de astronomia }\end{array}$ & $\begin{array}{l}\text { Tese (Doutorado em Educação para a } \\
\text { Ciência) - Universidade Estadual Pau- } \\
\text { lista, Bauru, 2013. }\end{array}$ & ES & $\begin{array}{l}\text { Formação de } \\
\text { professores }\end{array}$ \\
\hline LAGO, L. G. & Lua: fases e facetas de um conceito & $\begin{array}{l}\text { Dissertação (Mestrado em Ensino de } \\
\text { Ciências) - Universidade de São Paulo, } \\
\text { São Paulo, } 2013\end{array}$ & EF2 & $\begin{array}{l}\text { Conteúdo e } \\
\text { Método }\end{array}$ \\
\hline LANGHI, R. & $\begin{array}{l}\text { Um estudo exploratório para a inserção da } \\
\text { astronomia na formação de professores dos } \\
\text { anos iniciais do ensino fundamental }\end{array}$ & $\begin{array}{l}\text { Dissertação (Mestrado em Educação } \\
\text { para a Ciência) - Universidade Estadu- } \\
\text { al Paulista, Bauru, } 2004 .\end{array}$ & EF1 & $\begin{array}{l}\text { Formação de } \\
\text { professores }\end{array}$ \\
\hline LANGHI, R. & $\begin{array}{l}\text { Astronomia nos anos iniciais do ensino } \\
\text { fundamental: repensando a formação de } \\
\text { professores }\end{array}$ & $\begin{array}{l}\text { Tese (Doutorado em Educação para a } \\
\text { Ciência) - Universidade Estadual Pau- } \\
\text { lista, Bauru, } 2009 \text {. }\end{array}$ & $\mathrm{ES}, \mathrm{EF} 1$ & $\begin{array}{l}\text { Formação de } \\
\text { professores }\end{array}$ \\
\hline LEITE, C. & $\begin{array}{l}\text { Formação do professor de ciências em as- } \\
\text { tronomia: uma proposta com enfoque na } \\
\text { espacialidade }\end{array}$ & $\begin{array}{l}\text { Tese (Doutorado em Educação) - Fa- } \\
\text { culdade de Educação, Universidade de } \\
\text { São Paulo, 2006. }\end{array}$ & $\mathrm{ES}, \mathrm{EF} 2$ & $\begin{array}{l}\text { Formação de } \\
\text { professores }\end{array}$ \\
\hline LEITE, C. & $\begin{array}{l}\text { Os professores de ciências e suas formas } \\
\text { de pensar a astronomia }\end{array}$ & $\begin{array}{l}\text { Dissertação (Mestrado em Ensino de } \\
\text { Ciências) - Universidade de São Paulo, } \\
\text { São Paulo, } 2002 .\end{array}$ & EF2 & $\begin{array}{l}\text { Característica de } \\
\text { professor }\end{array}$ \\
\hline LIMA, M. L. S. & $\begin{array}{l}\text { Saberes de astronomia no } 1^{0} \text { e } 2^{\circ} \text { ano do } \\
\text { ensino fundamental numa perspectiva de } \\
\text { letramento e inclusão }\end{array}$ & $\begin{array}{l}\text { Dissertação (Mestrado em Ensino de } \\
\text { Astronomia) - Universidade Federal do } \\
\text { Rio Grande do Norte, Natal, } 2006\end{array}$ & EF1 & $\begin{array}{l}\text { Conteúdo e } \\
\text { método }\end{array}$ \\
\hline MACÊDO, J. A. & $\begin{array}{l}\text { Formação inicial de professores de ciências } \\
\text { da natureza e matemática e o ensino de } \\
\text { astronomia }\end{array}$ & $\begin{array}{l}\text { Dissertação (Mestrado em Ensino de } \\
\text { Ciências e Matemática) - Pontifícia } \\
\text { Universidade Católica de Minas Gerais, } \\
\text { Belo Horizonte, } 201\end{array}$ & ES & $\begin{array}{l}\text { Formação de } \\
\text { professores }\end{array}$ \\
\hline $\begin{array}{l}\text { MARRONE JUNIOR., } \\
\text { J. }\end{array}$ & $\begin{array}{l}\text { Um perfil da pesquisa em ensino de astro- } \\
\text { nomia no Brasil a partir da análise de perió- } \\
\text { dicos de ensino de ciências }\end{array}$ & $\begin{array}{l}\text { Dissertação (Mestrado em Ensino de } \\
\text { Ciências e Educação Matemática) - } \\
\text { Universidade Estadual de Londrina, } \\
\text { Londrina, 2007. }\end{array}$ & Geral & $\begin{array}{l}\text { Outros (estado } \\
\text { da arte) }\end{array}$ \\
\hline MENEZES, D. P & $\begin{array}{l}\text { Universo, terra e vida: orientando o profes- } \\
\text { sor no trabalho com alunos surdos }\end{array}$ & $\begin{array}{l}\text { Dissertação (Mestrado) - Centro Fede- } \\
\text { ral de Educação Tecn. Celso Suckow } \\
\text { da Fonseca, Rio de Janeiro, } 2010\end{array}$ & EM & $\begin{array}{l}\text { Conteúdo e } \\
\text { método }\end{array}$ \\
\hline PELLENZ, D. & $\begin{array}{l}\text { Astronomia no ensino de ciências: uma pro- } \\
\text { posta potencialmente significativa }\end{array}$ & $\begin{array}{l}\text { Dissertação (Mestrado em Ensino de } \\
\text { Ciências e Matemática) - Universidade } \\
\text { de Caxias do Sul, Caxias do Sul, } 2015 .\end{array}$ & EF2 & $\begin{array}{l}\text { Conteúdo e } \\
\text { método }\end{array}$ \\
\hline PESQUERO, L. C. & $\begin{array}{l}\text { Proposta de um minicurso de astronomia } \\
\text { para alunos do ensino fundamental II }\end{array}$ & $\begin{array}{l}\text { Dissertação (Mestrado em Ensino de } \\
\text { Física) - Universidade Federal de São } \\
\text { Carlos, São Carlos, } 2015 .\end{array}$ & EF2 & $\begin{array}{l}\text { Conteúdo e } \\
\text { método }\end{array}$ \\
\hline
\end{tabular}




\begin{tabular}{|c|c|c|c|c|}
\hline Autor(a) & Título & Referência & Nível escolar & Foco \\
\hline PUZZO, D. & $\begin{array}{l}\text { Um estudo das concepções alternativas } \\
\text { presentes em professores de } 5^{\text {a }} \text { série do } \\
\text { ensino fundamental sobre as fases da lua } \\
\text { e eclipses }\end{array}$ & $\begin{array}{l}\text { Dissertação (Mestrado em Ensino de } \\
\text { Ciências e Educação Matemática) - } \\
\text { Universidade Estadual de Londrina, } \\
\text { Londrina, } 2005 .\end{array}$ & EF2 & $\begin{array}{l}\text { Característica de } \\
\text { professor }\end{array}$ \\
\hline QUEIROZ, A. S. B. & $\begin{array}{l}\text { Propostas e discussões para o ensino de } \\
\text { astronomia nos } 1^{\circ} \text { e } 2^{\circ} \text { ciclos do nível funda- } \\
\text { mental e na educação de jovens e adultos }\end{array}$ & $\begin{array}{l}\text { Dissertação (Mestrado em Ensino de } \\
\text { Astronomia) - Universidade Federal } \\
\text { do Rio Grande do Norte, Natal, } 2005 .\end{array}$ & EF1, EF2, EM & Conteúdo e método \\
\hline QUEIROZ, V. & $\begin{array}{l}\text { A astronomia presente nas séries iniciais do } \\
\text { ensino fundamental das escolas municipais } \\
\text { de Londrina }\end{array}$ & $\begin{array}{l}\text { Dissertação (Mestrado em Ensino de } \\
\text { Ciências e Educação Matemática) - } \\
\text { Universidade Estadual de Londrina, } \\
\text { Londrina, } 2008 .\end{array}$ & EF1 & Currículos e programas \\
\hline SANTIAGO, A. V. R. & $\begin{array}{l}\text { O potencial da observação no ensino de } \\
\text { astronomia: um estudo do conceito energia }\end{array}$ & $\begin{array}{l}\text { Dissertação (Mestrado em Ensino de } \\
\text { Ciências) - Universidade de São Pau- } \\
\text { lo, São Paulo, } 2002 .\end{array}$ & EM & Conteúdo e método \\
\hline SANTOS, L. T. & $\begin{array}{l}\text { O olhar do toque: aprendendo com o aluno } \\
\text { cego a tecer o ensino de física }\end{array}$ & $\begin{array}{l}\text { Dissertação (Mestrado em Ensino de } \\
\text { Ciências) - Universidade de São Pau- } \\
\text { lo, São Paulo, } 2001 .\end{array}$ & EM & Conteúdo e método \\
\hline SILVA, F. M. & $\begin{array}{l}\text { Mediação computacional como fator de } \\
\text { motivação de aprendizagem significativa no } \\
\text { ensino de astronomia }\end{array}$ & $\begin{array}{l}\text { TeDissertação (Mestrado em Educa- } \\
\text { ção em Ciências e Matemática) - Uni- } \\
\text { versidade Fedral de Goiás, Goiânia, } \\
\text { 2010.. }\end{array}$ & EF2 & Recursos didáticos \\
\hline SILVA, T. P. & $\begin{array}{l}\text { Nossa posição no universo: uma proposta } \\
\text { de sequência didática para o ensino de as- } \\
\text { tronomia no ensino médio }\end{array}$ & $\begin{array}{l}\text { Dissertação (Mestrado Profissional } \\
\text { em Ensino de Física) - Universidade } \\
\text { Federal do Espírito Santo, Vitória, } \\
2015 .\end{array}$ & EM & Conteúdo e método \\
\hline SOARES, L. M. & $\begin{array}{l}\text { Apropriação e domínio de instrumentos } \\
\text { para o ensino de astronomia }\end{array}$ & $\begin{array}{l}\text { Dissertação (Mestrado Profissional } \\
\text { em Educação) - Universidade Federal } \\
\text { de Minas Gerais, Belo Horizonte, } 2010 .\end{array}$ & EF1, EF2, EM, ES & Recursos didáticos \\
\hline SOLER, D. R. & $\begin{array}{l}\text { Astronomia no currículo do estado de São } \\
\text { Paulo e nos PCN: um olhar para o tema ob- } \\
\text { servação do céu }\end{array}$ & $\begin{array}{l}\text { Dissertação (Mestrado em Ensino de } \\
\text { Ciências) - Universidade de São Pau- } \\
\text { lo, São Paulo, } 2012 .\end{array}$ & EF2, EM & Currículos e programas \\
\hline VALENTE, J. A. S & $\begin{array}{l}\text { A construção de conceitos relacionados } \\
\text { com os movimentos terra-lua-sol por alunos } \\
\text { da EJA à luz da teoria histórico-cultural }\end{array}$ & $\begin{array}{l}\text { Dissertação (Mestrado em Educação } \\
\text { em Ciências e Matemáticas) - Uni- } \\
\text { versidade de Federal do Pará, Belém, } \\
2007\end{array}$ & EM & Formação de conceitos \\
\hline
\end{tabular}

Fonte: Elaborado pelos autores.

\section{Anexo B - Artigos de periódicos analisados}

\begin{tabular}{|c|c|c|c|c|}
\hline Autor(a) & Título & Referência & Nível & Foco \\
\hline CAMINO, N. & Aprender Astronomía jugando en una plaza & $\begin{array}{l}\text { RELEA, São Carlos, n. } 14 \text {, p. } 39-56 \text {, } \\
2012 .\end{array}$ & Geral & Recursos didáticos \\
\hline $\begin{array}{l}\text { DARROZ, L. M.; PÉ- } \\
\text { REZ, C. A. S.; ROSA, } \\
\text { C. W.; HEINECK, R. }\end{array}$ & $\begin{array}{l}\text { Propiciando aprendizagem significativa } \\
\text { para alunos do sexto ano do ensino funda- } \\
\text { mental: um estudo sobre as fases da Lua }\end{array}$ & $\begin{array}{l}\text { RELEA, São Carlos, n. 13, p. 31-40, } \\
2012 .\end{array}$ & EF2 & Conteúdo e método \\
\hline $\begin{array}{l}\text { DARROZ, L. M.; } \\
\text { ROSA, C. W.; ROSA, } \\
\text { A. B.; PÉREZ, C. A. S. }\end{array}$ & $\begin{array}{l}\text { Evolução dos conceitos de astronomia no } \\
\text { decorrer da educação básica }\end{array}$ & $\begin{array}{l}\text { RELEA, São Carlos, n. 12, p. 107-121, } \\
2014 .\end{array}$ & EF2, EM & $\begin{array}{l}\text { Característica de } \\
\text { aluno }\end{array}$ \\
\hline $\begin{array}{l}\text { DARROZ, L. M.; } \\
\text { HEINECK, R.; PÉREZ, } \\
\text { C. A. S. }\end{array}$ & $\begin{array}{l}\text { Conceitos básicos de astronomia: uma pro- } \\
\text { posta metodológica }\end{array}$ & $\begin{array}{l}\text { RELEA, São Carlos, n. 12, p. 57-69, } \\
2011 .\end{array}$ & EM & Conteúdo e método \\
\hline $\begin{array}{l}\text { DARROZ, L. M.; } \\
\text { ROSA, C. W.; VIZZO- } \\
\text { TO, P. A.; ROSA, A. B. }\end{array}$ & $\begin{array}{l}\text { As fases da lua e os acontecimentos ter- } \\
\text { restres: a crença de diferentes níveis de } \\
\text { instrução }\end{array}$ & $\begin{array}{l}\text { RELEA, São Carlos, n. 16, p. 73-85, } \\
2013 .\end{array}$ & Geral & $\begin{array}{l}\text { Característica de } \\
\text { aluno }\end{array}$ \\
\hline $\begin{array}{l}\text { FAGUNDES, A. L.; } \\
\text { SILVA, T.; BARROSO, } \\
\text { M. F. }\end{array}$ & $\begin{array}{l}\text { Aprendizagem mediada por uma hipermídia } \\
\text { educacional }\end{array}$ & $\begin{array}{l}\text { RELEA, São Carlos, n. 20, p. 91-114, } \\
2015 .\end{array}$ & ES & Recursos didáticos \\
\hline $\begin{array}{l}\text { GIOVANNINI, O.; PEL- } \\
\text { LENZ, D.; CATELLI, F. }\end{array}$ & O lado escuro da lua nunca apanha sol? & $\begin{array}{l}\text { RELEA, São Carlos, n. 17, p. 91-106, } \\
2014 .\end{array}$ & EF2 & Conteúdo e método \\
\hline $\begin{array}{l}\text { GOMIDE, H. A.; } \\
\text { LONGHINI, M. D. }\end{array}$ & $\begin{array}{l}\text { Análise da presença de conteúdos de astro- } \\
\text { nomia em uma década do exame nacional } \\
\text { do ensino médio (1998-2008) }\end{array}$ & $\begin{array}{l}\text { RELEA, São Carlos, n. 11, p. 31-43, } \\
2011 .\end{array}$ & EM & $\begin{array}{l}\text { Currículos e pro- } \\
\text { gramas }\end{array}$ \\
\hline $\begin{array}{l}\text { GONZATTI, S. E. M. } \\
\text { et al. }\end{array}$ & $\begin{array}{l}\text { Ensino de astronomia: cenários da prática } \\
\text { docente no ensino fundamental }\end{array}$ & $\begin{array}{l}\text { RELEA, São Carlos, n. 16, p. } 27-43 \text {, } \\
2013 .\end{array}$ & EF1,EF2 & $\begin{array}{l}\text { Característica de } \\
\text { professor }\end{array}$ \\
\hline
\end{tabular}




\begin{tabular}{|c|c|c|c|c|}
\hline Autor(a) & Título & Referência & Nível & Foco \\
\hline $\begin{array}{l}\text { HEYER, I.; SLATER, S. } \\
\text { J.; SLATER, T. F. }\end{array}$ & $\begin{array}{l}\text { Establishing the empirical relationship between } \\
\text { non-science majoring undergraduate learners' } \\
\text { spatial thinking skills and their conceptual as- } \\
\text { tronomy knowledge }\end{array}$ & $\begin{array}{l}\text { RELEA, São Carlos, n. 16, p. 45-61, } \\
2013 .\end{array}$ & ES & Característica de aluno \\
\hline $\begin{array}{l}\text { IACHEL, G.; LANGHI, R.; } \\
\text { SCALVI, R. M. F. }\end{array}$ & $\begin{array}{l}\text { Concepções alternativas de alunos do ensino } \\
\text { médio sobre o fenômeno de formação das fa- } \\
\text { ses da lua }\end{array}$ & $\begin{array}{l}\text { RELEA, São Carlos, n. 5, p. 25-37, } \\
2008 .\end{array}$ & EM & Característica de aluno \\
\hline JAFELICE, L. C. & $\begin{array}{l}\text { Astronomia cultural nos ensinos fundamental } \\
\text { e médio }\end{array}$ & $\begin{array}{l}\text { RELEA, São Carlos, n. 19, p. 57-92, } \\
2015 .\end{array}$ & Geral & Conteúdo e método \\
\hline LANGHI, R.; NARDI, R. & $\begin{array}{l}\text { Dificuldades interpretadas nos discursos de } \\
\text { professores dos anos iniciais do ensino funda- } \\
\text { mental em relação ao ensino da astronomia }\end{array}$ & $\begin{array}{l}\text { RELEA, São Carlos, n. 2, p. 75-92, } \\
2005 .\end{array}$ & ES, EF1 & $\begin{array}{l}\text { Característica de } \\
\text { professor }\end{array}$ \\
\hline LEITE, C.; HOSOUME, Y. & $\begin{array}{l}\text { Os professores de ciências e suas formas de } \\
\text { pensar a astronomia }\end{array}$ & $\begin{array}{l}\text { RELEA, São Carlos, n. 4, p. 47-68, } \\
2007 .\end{array}$ & EF2 & $\begin{array}{l}\text { Característica de } \\
\text { professor }\end{array}$ \\
\hline $\begin{array}{l}\text { LONGHINI, M. D.; GOMI- } \\
\text { DE, H. A. }\end{array}$ & $\begin{array}{l}\text { Aprendendo sobre o céu a partir do entorno: } \\
\text { uma experiência de trabalho ao longo de um } \\
\text { ano com alunos de ensino fundamental }\end{array}$ & $\begin{array}{l}\text { RELEA, São Carlos, n. 18, p. 49-71, } \\
2014 .\end{array}$ & EF2 & Conteúdo e método \\
\hline $\begin{array}{l}\text { MACHADO, D. I.; SAN- } \\
\text { TOS, C. }\end{array}$ & $\begin{array}{l}0 \text { entendimento de conceitos de Astronomia } \\
\text { por alunos da educação básica: o caso de uma } \\
\text { escola pública brasileira }\end{array}$ & $\begin{array}{l}\text { RELEA, São Carlos, n. 11, p. 7-29, } \\
2011 .\end{array}$ & $\mathrm{EF}, \mathrm{EM}$ & Característica de aluno \\
\hline $\begin{array}{l}\text { MARTINS, B. A.; LANGHI, } \\
\text { R. }\end{array}$ & $\begin{array}{l}\text { Uma proposta de atividade para a aprendiza- } \\
\text { gem significativa sobre fases da lua }\end{array}$ & $\begin{array}{l}\text { RELEA, São Carlos, n. 14, p. 27-36, } \\
2012 .\end{array}$ & EM & Conteúdo e método \\
\hline $\begin{array}{l}\text { MORETT, S. S.; SOUZA, } \\
\text { M. O }\end{array}$ & $\begin{array}{l}\text { Desenvolvimento de recursos pedagógicos } \\
\text { para inserir o ensino de astronomia nas séries } \\
\text { iniciais do ensino fundamental }\end{array}$ & $\begin{array}{l}\text { RELEA, São Carlos, n. 8, p. 7-17, } \\
2009 .\end{array}$ & EF1 & Conteúdo e método \\
\hline $\begin{array}{l}\text { MOTA, A. T.; BONOMINI, } \\
\text { I. A. M.; ROSADO, R. } \\
\text { M. M. }\end{array}$ & $\begin{array}{l}\text { Inclusão de temas astronômicos numa aborda- } \\
\text { gem inovadora do ensino informal de física para } \\
\text { estudantes do ensino médio }\end{array}$ & $\begin{array}{l}\text { RELEA, São Carlos, n. 8, p. 7-17, } \\
2009 .\end{array}$ & EM & Conteúdo e método \\
\hline $\begin{array}{l}\text { OLIVEIRA, E. F.; VOEL- } \\
\text { ZKE, M. R.; AMARAL, } \\
\text { L. H. }\end{array}$ & $\begin{array}{l}\text { Percepção astronômica de um grupo de alunos } \\
\text { do ensino médio da rede estadual de São Paulo } \\
\text { da cidade de Suzano }\end{array}$ & $\begin{array}{l}\text { RELEA, São Carlos, n. 4, p. 79-99, } \\
2007 .\end{array}$ & EM & Característica de aluno \\
\hline $\begin{array}{l}\text { QUEIROZ, G. P.; SOUSA, } \\
\text { C. J. B.; MACHADO, M. } \\
\text { A. D. }\end{array}$ & $\begin{array}{l}\text { A prática de pesquisa de um professor do en- } \\
\text { sino fundamental envolvendo modelos mentais } \\
\text { de fases da lua e eclipses }\end{array}$ & $\begin{array}{l}\text { RELEA, São Carlos, n. 8, p. 16-36, } \\
2009 .\end{array}$ & ES, EF2 & $\begin{array}{l}\text { Característica de } \\
\text { professor }\end{array}$ \\
\hline SARAIVA, M. F. O. et al. & As fases da lua numa caixa de papelão & $\begin{array}{l}\text { RELEA, São Carlos, n. 4, p. 9-26, } \\
2007 .\end{array}$ & Geral & Recursos didáticos \\
\hline $\begin{array}{l}\text { SARAIVA, M. F. O.; SIL- } \\
\text { VEIRA, F. L.; STEFFANI, } \\
\text { M. H. }\end{array}$ & $\begin{array}{l}\text { Concepções de estudantes universitários sobre } \\
\text { fases da lua }\end{array}$ & $\begin{array}{l}\text { RELEA, São Carlos, n. 11, p. 63-80, } \\
2011 .\end{array}$ & ES & Característica de aluno \\
\hline $\begin{array}{l}\text { SILVEIRA, F. P. R. A.; } \\
\text { MENDONÇA, C. A. S. . }\end{array}$ & $\begin{array}{l}\text { O mapa conceitual como recurso didático faci- } \\
\text { litador da aprendizagem significativa de temas } \\
\text { da astronomia }\end{array}$ & $\begin{array}{l}\text { RELEA, São Carlos, n. 19, p. 93- } \\
121,2015 .\end{array}$ & EF2 & Conteúdo e método \\
\hline $\begin{array}{l}\text { SILVEIRA, F. P. R. A.; } \\
\text { SOUSA, C. M. S. G.; } \\
\text { MOREIRA, M. A. . }\end{array}$ & $\begin{array}{l}\text { Uma avaliação diagnóstica para o ensino da } \\
\text { astronomia }\end{array}$ & $\begin{array}{l}\text { RELEA, São Carlos, n. 13, p. 41-59, } \\
2011 .\end{array}$ & EF2 & Característica de aluno \\
\hline $\begin{array}{l}\text { SOARES, L. M. S.; } \\
\text { NASCIMENTO, S. S. }\end{array}$ & $\begin{array}{l}\text { Formas de apropriação de instrumentos para o } \\
\text { ensino de astronomia na formação continuada } \\
\text { de professores }\end{array}$ & $\begin{array}{l}\text { RELEA, São Carlos, n. 11, p. 45-62, } \\
2012 .\end{array}$ & ES & Formação de professor \\
\hline $\begin{array}{l}\text { AGUIAR, C. E.; BARONI, } \\
\text { D.; FARINA, C. }\end{array}$ & A órbita da lua vista do sol & RBEF, São Paulo, v. 31, n. 4, 2009. & Geral & Conteúdo específico \\
\hline KULESZA, W. & $\begin{array}{l}\text { Previsão astronômica através da observação } \\
\text { das marés }\end{array}$ & RBEF, São Paulo, v. 10, 1988. & Geral & Conteúdo específico \\
\hline $\begin{array}{l}\text { SCARINCI, A. L.; PACCA, } \\
\text { J. L. A. }\end{array}$ & $\begin{array}{l}\text { Um curso de astronomia e as preconcepções } \\
\text { dos alunos }\end{array}$ & $\begin{array}{l}\text { RBEF, São Paulo, v. 28, n. 1, p. 89- } \\
99,2006 .\end{array}$ & EF2 & Característica de aluno \\
\hline SILVEIRA, F. L. & $\begin{array}{l}\text { As variações dos intervalos de tempo entre as } \\
\text { fases principais da lua }\end{array}$ & $\begin{array}{l}\text { RBEF, São Paulo, v. 23, n. 3, p. 300- } \\
307,2001 .\end{array}$ & Geral & Conteúdo Específico \\
\hline $\begin{array}{l}\text { SOLBES, J.; PALOMAR, } \\
\text { R. }\end{array}$ & $\begin{array}{l}\text { Dificultades en el aprendizaje de la astronomía } \\
\text { en secundaria }\end{array}$ & $\begin{array}{l}\text { RBEF, São Paulo, v. } 35, \text { n. 1, p. } \\
\text { 1-12, 2013. }\end{array}$ & EM & Característica de aluno \\
\hline TEIXEIRA JR., A. S. & Atividades para a classe: órbita da lua & $\begin{array}{l}\text { RBEF, São Paulo, v. 2, n. 1, p. 15- } \\
20,1980 .\end{array}$ & Geral & Conteúdo específico \\
\hline $\begin{array}{l}\text { TONEL, A. P. ; MARRAN- } \\
\text { GHELLO, G. F. }\end{array}$ & O movimento aparente da lua & $\begin{array}{l}\text { RBEF, São Paulo, v. 35, n. 2, p. 1-6, } \\
2013 .\end{array}$ & Geral & Conteúdo específico \\
\hline ALMEIDA, G. & $\begin{array}{l}\text { Sobre o tamanho aparente da lua no horizonte } \\
\text { e a maiores alturas }\end{array}$ & $\begin{array}{l}\text { CBEF, Florianópolis, v. 29, n. 2, p. } \\
325-335,2012 .\end{array}$ & Geral & Conteúdo específico \\
\hline
\end{tabular}


Ciên. Educ., v. 26, e20007, 2020

\begin{tabular}{|c|c|c|c|c|}
\hline Autor(a) & Título & Referência & Nível & Foco \\
\hline CANALLE, J. B. G. & $\begin{array}{l}\text { Explicando astronomia básica com uma bola de } \\
\text { isopor }\end{array}$ & $\begin{array}{l}\text { CBEF, Florianópolis, v. 16, n. 3, p. } \\
\text { 317-334, } 1999 .\end{array}$ & Geral & Recursos didáticos \\
\hline $\begin{array}{l}\text { DARROZ, L. M.; SAN- } \\
\text { TOS, F. M. T. }\end{array}$ & $\begin{array}{l}\text { Astronomia: uma proposta para promover a } \\
\text { aprendizagem significativa de conceitos básicos } \\
\text { de astronomia na formação de professores em } \\
\text { nível médio }\end{array}$ & $\begin{array}{l}\text { CBEF, Florianópolis, v. 30, n. 1, p. } \\
\text { 104-130, 2013. }\end{array}$ & EM, EF1 & Formação de professor \\
\hline LANGHI, R. & $\begin{array}{l}\text { Educação em astronomia: da revisão bibliográfi- } \\
\text { ca sobre concepções alternativas à necessidade } \\
\text { de uma ação nacional }\end{array}$ & $\begin{array}{l}\text { CBEF, Florianópolis, v. 28, n. 2, p. } \\
\text { 373-399, } 2011 .\end{array}$ & Geral & $\begin{array}{l}\text { Características de aluno } \\
\text { e de professor }\end{array}$ \\
\hline $\begin{array}{l}\text { LONGHINI, M. D.; MENE- } \\
\text { ZES, L. D. D. }\end{array}$ & $\begin{array}{l}\text { Objeto virtual de aprendizagem no ensino de } \\
\text { astronomia: algumas situações problemas pro- } \\
\text { postas a partir do software Stellarium }\end{array}$ & $\begin{array}{l}\text { CBEF, Florianópolis, v. } 27, \text { n. 3, p. } \\
433-448,2010 .\end{array}$ & Geral & Recursos didáticos \\
\hline LOPES, W. & Eclipse total da lua & $\begin{array}{l}\text { CBEF, Florianópolis, v. 31, n. 2, p. } \\
400-409,2014 .\end{array}$ & Geral & Conteúdo específico \\
\hline $\begin{array}{l}\text { MARRONE JUNIOR, M.; } \\
\text { TREVISAN, R. T. }\end{array}$ & $\begin{array}{l}\text { Um perfil da pesquisa em ensino de astronomia } \\
\text { no Brasil a partir da análise de periódicos de en- } \\
\text { sino de ciências }\end{array}$ & $\begin{array}{l}\text { CBEF, Florianópolis, v. } 26, \text { n. } 3 \text {, p. } \\
547-574,2009 .\end{array}$ & Geral & Outros \\
\hline $\begin{array}{l}\text { PINTO, S. P. ; FONSECA, } \\
\text { O. M.; VIANNA, D. M. }\end{array}$ & $\begin{array}{l}\text { Formação continuada de professores: estratégia } \\
\text { para o ensino de astronomia nas séries iniciais }\end{array}$ & $\begin{array}{l}\text { CBEF, Florianópolis, v. 24, n. 1, p. } 71- \\
86,2007 .\end{array}$ & ES, EF1 & Formação de professor \\
\hline SILVA, T. & $\begin{array}{l}\text { Ensino a distância e tecnologias na educação: } 0 \\
\text { estudo de fenômenos astronômicos }\end{array}$ & $\begin{array}{l}\text { CBEF, Florianópolis, v. 26, n. 3, p. } \\
533-546,2009 .\end{array}$ & Geral & Recursos didáticos \\
\hline SILVEIRA, F. L. & Marés, fases principais da lua e bebês & $\begin{array}{l}\text { CBEF, Florianópolis, v. 20, n. 1, p. } 10- \\
29,2003 .\end{array}$ & Geral & Conteúdo específico \\
\hline $\begin{array}{l}\text { SILVEIRA, F. L.; MEDEI- } \\
\text { ROS }\end{array}$ & A ilusão sobre o tamanho da Lua no horizonte & $\begin{array}{l}\text { A Física na Escola, São Paulo, v. 7, n. } \\
\text { 2, p. 67-69, 2006. }\end{array}$ & Geral & Conteúdo específico \\
\hline $\begin{array}{l}\text { SILVEIRA, F. L.; SARAI- } \\
\text { VA, M. F. O. }\end{array}$ & As cores da lua cheia & $\begin{array}{l}\text { A Física na Escola, São Paulo, v. 9, n. } \\
\text { 2, p. 20-24, 2008. }\end{array}$ & Geral & Conteúdo específico \\
\hline KRINER, A. & $\begin{array}{l}\text { Las fases de la luna: ¿cómo y cuándo enseñar- } \\
\text { las? }\end{array}$ & $\begin{array}{l}\text { C\&E, Bauru, v. 10, n. 1, p. 111-120, } \\
2004 .\end{array}$ & Geral & Conteúdo e método \\
\hline $\begin{array}{l}\text { BRETONES, P. S.; } \\
\text { COMPIANI, M. }\end{array}$ & $\begin{array}{l}\text { Tutoria na formação de professores para a ob- } \\
\text { servação do movimento anual da esfera celeste } \\
\text { e das chuvas de meteoros }\end{array}$ & $\begin{array}{l}\text { RBPC, Rio de Janeiro, v. 12, n.3, p. } \\
43-66,2012 .\end{array}$ & ES, EF2 & Formação de professor \\
\hline $\begin{array}{l}\text { MACHADO, M. A. D.; } \\
\text { QUEIROZ, G. R. P. C. }\end{array}$ & $\begin{array}{l}\text { A cultura de projetos, construída via parceria es- } \\
\text { cola-universidade, contribuindo para a qualidade } \\
\text { de formação inicial e continuada de professores }\end{array}$ & $\begin{array}{l}\text { RBPC, Rio de Janeiro, v. 12, n.1, p. } \\
93-116,2012 .\end{array}$ & ES, EF2 & Formação de professor \\
\hline $\begin{array}{l}\text { PAULA, H. F.; LIMA, M. } \\
\text { E. C. C. }\end{array}$ & Formulações de questões e mediação da leitura & $\begin{array}{l}\text { IENCl, Porto Alegre, v. 15, n. 3, p. } \\
429-461,2010 .\end{array}$ & Geral & Conteúdo e método \\
\hline $\begin{array}{l}\text { BRETONES, P. S.; } \\
\text { COMPIANI, M. }\end{array}$ & $\begin{array}{l}\text { A observação do céu como ponto de partida e } \\
\text { eixo central em um curso de formação continua- } \\
\text { da de professores }\end{array}$ & $\begin{array}{l}\text { Ensaio, Belo Horizonte, v. 12, n. 2, p. } \\
\text { 173-188, } 2010 .\end{array}$ & ES, EF2 & Conteúdo e método \\
\hline DARROZ; SANTOS & $\begin{array}{l}\text { Promovendo a aprendizagem significativa de } \\
\text { conceitos básicos de astronomia na formação de } \\
\text { professores em nível médio }\end{array}$ & $\begin{array}{l}\text { EENCl, Cuiabá, v. 7, n. 2, p. 1-13, } \\
2012 .\end{array}$ & EM, EF1 & Formação de professor \\
\hline $\begin{array}{l}\text { BRETONES, P. S.; } \\
\text { COMPIANI, M. }\end{array}$ & $\begin{array}{l}\text { Tutoria na formação de professores para o tema } \\
\text { movimentos da lua }\end{array}$ & $\begin{array}{l}\text { Alexandria, Florianópolis, v. 7, n. 1, p. } \\
\text { 23-47, } 2014 .\end{array}$ & ES, EF2 & Formação de professor \\
\hline
\end{tabular}

Fonte: elaborado pelo autores.

\section{Anexo C - Trabalhos apresentados em eventos}

\begin{tabular}{|l|c|l|l|l|l|}
\hline \multicolumn{1}{|c|}{ Autor(a) } & Ano & \multicolumn{1}{c|}{ Título } & \multicolumn{1}{c|}{ Evento } & Nível & \multicolumn{1}{c|}{ Foco } \\
\hline $\begin{array}{l}\text { CANALLE, J. B. G.; ZÁRA- } \\
\text { TE, J. D. B. }\end{array}$ & 2008 & $\begin{array}{l}\text { Análise das concepções que os alunos têm so- } \\
\text { bre as fases da lua. }\end{array}$ & $\begin{array}{l}\text { 34. Reunião Anual da } \\
\text { SAB }\end{array}$ & $\begin{array}{l}\text { EF } \\
\text { Característica de } \\
\text { aluno }\end{array}$ \\
\hline $\begin{array}{l}\text { COSTA, J. R. V.; GERMA- } \\
\text { NO, A. S. M. }\end{array}$ & 2011 & $\begin{array}{l}\text { A aprendizagem sobre as fases da lua numa } \\
\text { disciplina de astronomia na modalidade a dis- } \\
\text { tância }\end{array}$ & $\begin{array}{l}\text { 1. SNEA } \\
\text { aluno }\end{array}$ \\
\hline $\begin{array}{l}\text { LAGO, L. G.; MATTOS, } \\
\text { C. R. }\end{array}$ & 2011 & $\begin{array}{l}\text { A concepção das fases da lua como a sombra } \\
\text { da Terra: uma discussão à luz do perfil concei- } \\
\text { tual e da teoria da atividade }\end{array}$ & $\begin{array}{l}\text { 36. Reunião Anual da } \\
\text { SAB }\end{array}$ & ES & $\begin{array}{l}\text { Característica de } \\
\text { aluno }\end{array}$ \\
\hline $\begin{array}{l}\text { LAGO, L. G.; MATTOS, } \\
\text { C. R. }\end{array}$ & 2012 & $\begin{array}{l}\text { Fases da lua: uma aproximação do sistema de } \\
\text { conceitos (Vygotsky) com o sistema de ativida- } \\
\text { de (Leontiev) }\end{array}$ & 2. SNEA & Geral & $\begin{array}{l}\text { Formação de } \\
\text { conceitos }\end{array}$ \\
\hline
\end{tabular}




\begin{tabular}{|c|c|c|c|c|c|}
\hline Autor(a) & Ano & Título & Evento & Nível & Foco \\
\hline $\begin{array}{l}\text { LIMA, M. G. G. C.; } \\
\text { SILVA, T. C. C. }\end{array}$ & 2012 & $\begin{array}{l}\text { O movimento aparente da lua no céu: um dis- } \\
\text { positivo didático. }\end{array}$ & $\begin{array}{l}\text { 37. Reunião Anual da } \\
S A B\end{array}$ & Geral & Recursos didáticos \\
\hline $\begin{array}{l}\text { MARQUES, J. B. } \\
\text { et al. }\end{array}$ & 2002 & $\begin{array}{l}\text { A simple device showing the differences in } \\
\text { some moon's phases as seen by southern and } \\
\text { northern-hemisphere observers }\end{array}$ & $\begin{array}{l}\text { 28. Reunião Anual da } \\
S A B\end{array}$ & Geral & Recursos didáticos \\
\hline $\begin{array}{l}\text { MARTINS, B. A.; } \\
\text { LANGHI, R. }\end{array}$ & 2011 & $\begin{array}{l}\text { Aprendizagem significativa na elaboração de } \\
\text { histórias em quadrinhos sobre Astronomia por } \\
\text { alunos do ensino médio }\end{array}$ & 1. SNEA & EM & Conteúdo e método \\
\hline NOGUEIRA, E. C. & 2015 & Descobrindo a astronomia: as fases da lua & $\begin{array}{l}\text { 39. Reunião Anual da } \\
\text { SAB }\end{array}$ & ES & Recursos didáticos \\
\hline SELAU, F. F. et al. & 2012 & $\begin{array}{l}\text { Aventureiros do universo: com vejo a lua no } \\
\text { meu mundo? }\end{array}$ & $\begin{array}{l}\text { 37. Reunião Anual da } \\
\text { SAB }\end{array}$ & EF1 & Conteúdo e método \\
\hline $\begin{array}{l}\text { STEFFANI, M. H. ; } \\
\text { ZANATTA, C. V. }\end{array}$ & 2011 & $\begin{array}{l}\text { Astronomia com arte: estratégias para o ensino } \\
\text { a deficientes visuais }\end{array}$ & 1. SNEA & Geral & Conteúdo e método \\
\hline CAMARGO, L. et al. & 2014 & $\begin{array}{l}\text { As fases da lua: experiência com deficientes } \\
\text { visuais }\end{array}$ & 3. SNEA & Geral & Conteúdo e método \\
\hline $\begin{array}{l}\text { PELLENZ, D.; GIO- } \\
\text { VANNINI, O. }\end{array}$ & 2014 & $\begin{array}{l}\text { Unidade de ensino potencialmente significativa } \\
\text { para as fases da lua }\end{array}$ & 3. SNEA & EF2 & Conteúdo e método \\
\hline $\begin{array}{l}\text { VALÉRIO, t. V.; COR- } \\
\text { RÊA, H. P. S. }\end{array}$ & 2014 & Fases da lua: uma representação em 3D & 3. SNEA & EM & Conteúdo e método \\
\hline $\begin{array}{l}\text { TREVISAN, R. H. } \\
\text { et al. }\end{array}$ & 1993 & Instrumentação para o ensino de astronomia & 10. SNEF & $\mathrm{EF} 1$ e 2 & Conteúdo e método \\
\hline $\begin{array}{l}\text { ROMANO, A.; TREVI- } \\
\text { SAN, R. H.; LATTARI, } \\
\text { C. J. B. }\end{array}$ & 1999 & $\begin{array}{l}\text { Ensinando astronomia no primeiro e segundo } \\
\text { graus: observando as fases da lua }\end{array}$ & 13. SNEF & EF e EM & Conteúdo e método \\
\hline $\begin{array}{l}\text { SOARES, M. V.; } \\
\text { BRAGA, T. }\end{array}$ & 2007 & $\begin{array}{l}\text { A origem das crateras lunares: uma proposta } \\
\text { para ensinar elementos do método científico }\end{array}$ & 17. SNEF & ES (EM) & Conteúdo e método \\
\hline $\begin{array}{l}\text { ANDRADE, M. J. P.; } \\
\text { NEUBERGER, C. V.; } \\
\text { ARAÚJO, A. E. P. }\end{array}$ & 2009 & $\begin{array}{l}\text { As concepções de alunos do EJA sobre a lua: } \\
\text { um estudo exploratório }\end{array}$ & 18. SNEF & EF2 & $\begin{array}{l}\text { Característica de } \\
\text { aluno }\end{array}$ \\
\hline $\begin{array}{l}\text { AGUIAR, C. E.; } \\
\text { BARONI, D.; SOUZA, } \\
\text { C. F. }\end{array}$ & 2009 & A órbita da lua vista do sol & 18. SNEF & Geral & Conteúdo específico \\
\hline $\begin{array}{l}\text { SOARES NETO, F. F.; } \\
\text { FURTADO, W. W. }\end{array}$ & 2009 & $\begin{array}{l}\text { As fases da lua em histórias em quadrinhos no } \\
\text { ensino fundamental }\end{array}$ & 18. SNEF & EF2 & Recursos didáticos \\
\hline $\begin{array}{l}\text { COZENDEY, S. G.; } \\
\text { PESSANHA, M. C. R. }\end{array}$ & 2011 & $\begin{array}{l}\text { Modelo experimental para o ensino das fases } \\
\text { da lua aos indivíduos com e sem deficiência } \\
\text { visual }\end{array}$ & 19. SNEF & Geral & Recursos didáticos \\
\hline $\begin{array}{l}\text { MORETTI, L. R.; } \\
\text { SARAIVA, M. F. O.; } \\
\text { VEIT, E. A. }\end{array}$ & 2011 & $\begin{array}{l}\text { Concepções de alunos de ensino médio sobre } \\
\text { as fases da lua e as possíveis influências des- } \\
\text { se satélite na vida humana }\end{array}$ & 19. SNEF & EM & $\begin{array}{l}\text { Característica de } \\
\text { aluno }\end{array}$ \\
\hline $\begin{array}{l}\text { SAMPAIO, C. M.; } \\
\text { SANTOS, E. I. }\end{array}$ & 2011 & $\begin{array}{l}\text { Lua adversa: uma experiência entrelaçando } \\
\text { literatura e física }\end{array}$ & 19. SNEF & EM & Conteúdo e método \\
\hline CAMARGO, L. et al. & 2015 & $\begin{array}{l}\text { Auxiliando o ensino de astronomia para de- } \\
\text { ficientes visuais através da aplicação de um } \\
\text { experimento tátil }\end{array}$ & 21. SNEF & EM & Conteúdo e método \\
\hline $\begin{array}{l}\text { CARVALHO NETO, J. } \\
\text { T. et al. }\end{array}$ & 2015 & $\begin{array}{l}\text { Medindo a distância da Terra à lua: uma pro- } \\
\text { posta factível para o ensino médio }\end{array}$ & 21. SNEF & EM & Conteúdo e método \\
\hline $\begin{array}{l}\text { SANTIAGO, A. V. R.; } \\
\text { PACCA, J. L. A. }\end{array}$ & 2015 & $\begin{array}{l}\text { O conceito de energia a partir da observação } \\
\text { da lua: uma atividade experimental no ensino } \\
\text { médio }\end{array}$ & 21. SNEF & EM & Conteúdo e método \\
\hline $\begin{array}{l}\text { VALÉRIO, T. V.; } \\
\text { CORREA, H. P. S. }\end{array}$ & 2015 & Modelo dinâmico para o ensino de fases da lua & 21. SNEF & Não-escolar & Recursos didáticos \\
\hline $\begin{array}{l}\text { IACHEL, G.; LANGHI, } \\
\text { R.; SCALVI, R. M. F. }\end{array}$ & 2007 & $\begin{array}{l}\text { As fases da lua e as concepções alternativas } \\
\text { de alunos do ensino médio }\end{array}$ & 6. ENPEC & EM & $\begin{array}{l}\text { Característica de } \\
\text { aluno }\end{array}$ \\
\hline $\begin{array}{l}\text { SANTOS, J. H. M.; } \\
\text { PEREIRA, F. N. V.; } \\
\text { PENIDO, M. C. M. }\end{array}$ & 2011 & $\begin{array}{l}\text { Proposta de sequência didática para o ensino } \\
\text { de astronomia no fundamental: conhecendo a } \\
\text { lua }\end{array}$ & 8. ENPEC & $\mathrm{EF}$ & Conteúdo e método \\
\hline $\begin{array}{l}\text { SANTOS, J. H. M.; } \\
\text { PEREIRA, F. N. V.; } \\
\text { PENIDO, M. C. M. }\end{array}$ & 2011 & $\begin{array}{l}\text { Proposta de sequência didática para o ensino } \\
\text { de astronomia no fundamental: conhecendo a } \\
\text { lua }\end{array}$ & 8. ENPEC & $\mathrm{EF}$ & Conteúdo e método \\
\hline $\begin{array}{l}\text { FAGUNDES, A. L.; } \\
\text { BARROSO, M. F.; } \\
\text { SILVA, T. }\end{array}$ & 2013 & $\begin{array}{l}\text { Avaliação de aprendizagem sobre a rotação } \\
\text { síncrona da lua mediada por recurso compu- } \\
\text { tacional }\end{array}$ & 9. ENPEC & ES & Recursos didáticos \\
\hline
\end{tabular}

Fonte: elaborado pelos autores. 